\title{
Near-field horizontal and vertical earthquake ground
}

\section{motions}

\author{
N. N. Ambraseys ${ }^{a, *}$ J. Douglas ${ }^{a}$

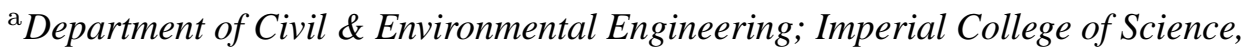 \\ Technology \& Medicine; London; SW7 2BU; U.K.
}

\begin{abstract}
Strong-motion attenuation relationships are presented for peak ground acceleration, spectral acceleration, energy density, maximum absolute input energy for horizontal and vertical directions and for the ratio of vertical to horizontal of these ground motion parameters. These equations were derived using a worldwide dataset of 186 strong-motion records recorded with $15 \mathrm{~km}$ of the surface projection of earthquakes between $M_{s}=5.8$ and 7.8. The effect of local site conditions and focal mechanism is included in some of these equations.
\end{abstract}

Key words: earthquake ground motions, peak ground acceleration, response spectra, vertical to horizontal ratios

* Corresponding author. Tel: +44 (0)20 7594 6059, Fax: +44 (0)20 72252716.

Email address: n. ambraseys@ic.ac.uk (N. N. Ambraseys). 


\section{Introduction}

Strong ground motions from close to large magnitude earthquakes are the most severe earthquake loading that structures undergo. However, in the past because of a lack of adequate strong-motion data from close to large magnitude earthquakes, equations to estimate strong ground motions have been derived mainly using strong-motion records from the intermediate- and far-field of earthquakes. In the past decade sufficient strong-motion records from close to large magnitude earthquakes have become available to derive equations for estimating ground motions using only such records. In this article we present such equations derived using a worldwide dataset of 186 strong-motion records recorded with $15 \mathrm{~km}$ of the surface projection of earthquakes between $M_{s}=5.8$ and 7.8.

The strong-motion parameters that we have chosen to examine are: horizontal and vertical peak ground acceleration and the ratio of these quantities, horizontal and vertical spectral acceleration and the ratios of these quantities, horizontal and vertical energy density and the ratio of these quantities and horizontal and vertical maximum absolute input energy and the ratio of these quantities. Peak ground acceleration is important because it fixes the zero period ordinate of response spectra, which are extensively used in seismic design, and is especially important for defining seismic code response spectra, which are commonly defined in terms of peak ground acceleration. Spectral acceleration is important because after multiplying it by mass it gives the maximum force that the single-degree-of-freedom system that models the structure will be subjected to during the earthquake. Recently interest in the use of energy based strong-motion parameters, such as examined in this article, for seismic hazard assessment [e.g. 26], seismic hazard disaggregation [e.g. 16] and seismic design [e.g. 8] has increased. All these uses of energy quantities require 
equations to estimate strong ground motions, such as provided in this article.

In this paper we examine the peak and spectral values of the vertical acceleration relative to the horizontal in the frequency and time domains to answer the question of whether the vertical component of ground motion constitutes a significant proportion of the inertial loading that has to be resisted by a building and by its foundations.

\section{Data and method used}

\subsection{Selection of records}

We selected 186 free-field, chiefly triaxial strong-motion records from 42 earthquakes following the free-field definition of Joyner and Boore [23] using the criteria: $M_{s} \geq 5.8, d \leq 15 \mathrm{~km}$ and $h \leq 20 \mathrm{~km}$. The chosen records and other tabulated material are listed in Ambraseys and Douglas [3]. The distribution of the records used with respect to geographical location and earthquake mechanism is given in Table 1. Figure 1 shows the distribution of the data with magnitude and distance. Although some authors have found evidence for differences in strong ground motions due to the tectonic environment [e.g. 28] the limited number of records fulfilling our selection criteria meant that we could not investigate this effect. However, all the records in our set came from active tectonic regions, except for two records from the Nahanni earthquake $\left(23 / 12 / 1985, M_{s}=6.8\right)$ which is from a stable continental region.

As can be seen from Figure 1 the records are well distributed in magnitude and distance, and consequently the equations obtained, based on this set of data are 
well constrained and representative of the entire dataspace: $0 \leq d \leq 15 \mathrm{~km}$ and $5.8 \leq M_{s} \leq 7.8$. The distribution with magnitude and distance of records from thrust and strike-slip earthquakes is also reasonably uniform. There is a lack of near-field recordings of earthquakes with normal mechanisms in the dataset used and there are no records from normal earthquakes with $M_{s}>6.9$ because of fault segmentation.

Site conditions at the stations are also given in Ambraseys and Douglas [3] using the categorisation proposed by Boore et al. [9], i.e. L: $V_{\mathrm{s}, 30}<180 \mathrm{~ms}^{-1}$ (very soft soil), S: $180 \leq V_{\mathrm{s}, 30}<360 \mathrm{~ms}^{-1}$ (soft soil), A: $360 \leq V_{\mathrm{s}, 30}<750 \mathrm{~ms}^{-1}$ (stiff soil), and R: $V_{\mathrm{s}, 30} \geq 750 \mathrm{~ms}^{-1}$ (rock). Soil profiles for many of the Californian and European stations are available, from which $V_{\mathrm{s}, 30}$ estimates were made directly. For other sites, station conditions were assessed from the conversion of reported site categories. Site conditions have been classified for 178 of the 186 records. The distribution of the records used with respect to site classification is given in Table 1.

The difference between ground motions for sites on the hanging wall and foot wall of faults [e.g. 2] is not considered here. This study uses distance to the surface projection of the rupture, $d$, rather than the distance to the rupture therefore some of the differences in estimated ground motions between hanging wall and foot wall sites is implicitly modelled because hanging wall sites have $d=0 \mathrm{~km}$ whereas foot wall sites have $d>0 \mathrm{~km}$, see for example Abrahamson and Somerville [2].

\subsection{Correction procedure}

Ideally all of the records used for this study should have been processed in a uniform way, for this to be possible the time-histories need to be available in uncor- 
rected format. Unfortunately some of the records (19) could only be obtained from the original data owners in corrected format. Since these records came from large earthquakes (the earthquakes had $M_{s}=6.5,6.8,7.0,7.1$ and 7.6), it was thought better to incorporate them in this study. The short period range of interest for this study of 0.1 to $2.0 \mathrm{~s}$, means that any differences in the correction procedure should make little difference. The 19 records corrected in a different way are labelled in Ambraseys and Douglas [3].

The uncorrected records were corrected using an elliptical filter [24] with pass band $0.2-25 \mathrm{~Hz}$. For this study the values of these parameters used were: roll-off frequency $1.001 \mathrm{~Hz}$, sampling interval $0.02 \mathrm{~s}$, ripple in pass-band 0.005 and ripple in stop-band 0.015 . This pass band was chosen because some of the records which we could not obtain in uncorrected form were corrected with a similar pass band. Also because of difference in quality between the different accelerograms used meant that a narrower pass band should be used than when all the records are of a uniform quality. The correction procedure though should not affect significantly the results within the period of interest. An instrumental correction was applied if the necessary characteristics were known for a particular record, most having the required characteristics.

\subsection{Model of ground motion}

The ground motion model used has the form:

$$
\log y=b_{1}+b_{2} M_{s}+b_{3} d+b_{\mathrm{A}} S_{\mathrm{A}}+b_{\mathrm{S}} S_{\mathrm{S}}
$$

where $M_{s}$ is the surface-wave magnitude, $d$ is the distance to the surface projection 
of the rupture plane, $S_{\mathrm{A}}$ takes the value of 1 if the site is classified as stiff soil (A) and 0 otherwise, and $S_{\mathrm{S}}$ takes the value of 1 if the site is classified as soft soil (S) and 0 otherwise. For rock, $S_{\mathrm{A}}=S_{\mathrm{S}}=0$.

The distance dependence was not defined in terms of $r=\sqrt{d^{2}+h^{2}}$ because if a depth term $h$ is included it is almost indistinguishable from zero and hence was dropped. Decay is assumed to be associated with anelastic effects due to large strains, which is reasonable in the near field. Geometric decay close to the rupture of large earthquakes is small because seismic waves are reaching the station from many parts of the long rupture, unlike in the far field where the source can be approximated by a point and hence geometric decay is important. Also since both the geometrical decay terms of the form $\log (d)$ and the anelastic terms of the form $d$ are highly correlated within the short distance range used in the study, they cannot be

found simultaneously. A function of the form: $\log y=c_{1}+c_{2} M_{s}+c_{3} \log \sqrt{d^{2}+c_{4}^{2}}$ was also tried and the results were almost identical to those for the adopted functional form. Therefore the type of attenuation (geometric or anelastic) assumed is unimportant for this set of records.

The largest horizontal component was used for deriving the following attenuation relations for consistency with previous work. All peak ground acceleration and spectral accelerations are in $\mathrm{ms}^{-2}$, all energy densities are in $\mathrm{cm}^{2} \mathrm{~s}^{-1}$ and all maximum absolute input energies are in $\mathrm{cm}^{2} \mathrm{~s}^{2}$.

\subsection{Regression method}

A number of different regression methods exist for deriving attenuation relations, which affect in different ways the predictive equations. There are two main types 
of regression techniques used: one-stage [e.g. 4] and two-stage [e.g. 23]. In the former the magnitude and distance coefficients are found simultaneously whereas in the latter the distance coefficients are found first and then, in the second step the magnitude coefficients are determined.

Within these categories there are also two further procedures, ordinary least squares estimation and random-effects (or maximum-likelihood) models [11, 12]. The first of these simply finds the coefficients which minimize the sum of squares of the residuals considering the error in each record to be independent from the other records. After the coefficients are determined the standard deviation is found for the entire equation.

In the random-effects technique the error is assumed to consist of two parts: an earthquake-to-earthquake component, which is the same for all records from the same earthquake, and a record-to-record component, which expresses the variability between each record not expressed by the earthquake-to-earthquake component. The standard deviation of these two errors is found along with the coefficients. This method is thought to take better account of the fact that each record from the same earthquake is not strictly independent.

Most authors find that the regression technique used does not affect the results obtained within the range of distance and magnitude that are of engineering interest $[4,7]$. However, some authors find that due to high correlation between a record's magnitude and distance, the one-stage method gives biased results [22, 21] and that the two-stage technique eliminates this bias.

These two studies were based on Japanese datasets where the depths and distances of the events are much larger than for this near-field study. In our case the magnitudes and distances used are not strongly correlated, in fact the correlation coeffi- 
cient $r_{M_{s}, d}=-0.10$. Therefore these results do not apply to this study.

Before deciding which regression method to use for this study, both one-stage and two-stage ordinary least squares were used to peak ground acceleration and spectral ordinates of the horizontal and vertical components. A comparison of the results shows almost identical distance dependence terms but quite large differences in the magnitude terms. For $M_{s}=6.8$ the predicted PGA from the two methods are similar, diverging for higher and lower magnitude. The two stage regression predicts higher accelerations for smaller magnitudes and lower accelerations for larger magnitudes. This is also observed for vertical PGA, and for horizontal and vertical spectral ordinates. These differences are found because the two-stage method gives more weight to the less well recorded larger magnitude earthquakes $\left(M_{s}>7.0\right)$, in particular the Kocaeli earthquake $\left(17 / 8 / 1999, M_{s}=7.8\right)$ which contributes two records to the set, than does the one-stage method. The PGA of the two Kocaeli records are much lower $\left(a_{h}=3.5 \mathrm{~ms}^{-2}\right.$ and $\left.a_{h}=2.2 \mathrm{~ms}^{-2}\right)$ than would be expected from such a large magnitude earthquake. After removing the two Kocaeli records from the set and repeating the regression analysis it was found that the magnitude coefficient changed significantly (from $b_{2}=0.151$ to $b_{2}=0.195$ ) for the two-stage method but less significantly for the one-stage method (from $b_{2}=0.202$ to $b_{2}=0.222$ ) for horizontal PGA. It was felt that the two-stage method gave undue weight to the two records from the Kocaeli earthquake, which may not be typical of records from large magnitude earthquakes. Therefore, in what follows we shall be using the one-stage method for the analysis. 


\subsection{Effect of site geology}

Site geology was included in this study following the methodology of Ambraseys et al. [7]. The residuals:

$$
\epsilon_{i}=\log \left(y_{i}\right)-b_{1}^{\prime}-b_{2}\left(M_{i}\right)-b_{3} d_{i}
$$

from the first stage of the regression are found. Then the regression is performed on:

$$
\epsilon=b_{4} S_{\mathrm{R}}+b_{5} S_{\mathrm{A}}+b_{6} S_{\mathrm{S}}
$$

where $S_{\mathrm{R}}$ takes the value 1 if the site is classified as rock and 0 otherwise, and $S_{\mathrm{A}}$ and $S_{S}$ are similarly defined for stiff (A) and soft (S) soil sites. Then new coefficients are defined as follows: $b_{1}=b_{1}^{\prime}+b_{4} ; b_{\mathrm{A}}=b_{5}-b_{4}$, and $b_{\mathrm{S}}=b_{6}-b_{4}$, and the error $\sigma$ is recalculated with respect to the site-dependent prediction, using only those records of known site conditions.

\section{Results}

Table 2 gives the coefficients and standard deviations of the equations for horizontal peak ground acceleration $\left(a_{h}\right)$, vertical peak ground acceleration $\left(a_{v}\right)$, vertical to horizontal absolute peak ground acceleration ratio $\left(q=a_{v} / a_{h}\right)$, vertical to horizontal simultaneous peak ground acceleration ratio $\left(q_{\text {sim }}\right)$, horizontal energy density $\left(E_{h}\right)$, vertical energy density $\left(E_{v}\right)$ and vertical to horizontal energy density ratio $\left(q_{E}=E_{v} / E_{h}\right)$. Whether the soil coefficients $\left(b_{A}\right.$ and $\left.b_{S}\right)$ are significant at the $5 \%$ 
level is also given in Table 2. Only coefficients that are significant at the $5 \%$ level are retained; if a coefficient was not significant then the regression was repeated with the coefficient which was not significant constrained to zero.

The vertical to horizontal simultaneous PGA ratio defined as, $q_{\mathrm{sim}}=a_{v}\left(t_{\max }\right) / a_{\mathrm{h}}$, where $a_{v}(t)$ is the vertical ground acceleration time-history, $a_{h}$ is the horizontal PGA and $t_{\max }$ is the time at which this peak occurs. It gives the vertical acceleration to be resisted by a structure at the time of the design horizontal acceleration.

The energy density, $E$, of an strong motion record is defined as $E=\frac{1}{4} S \rho \int_{0}^{T} v(t)^{2} \mathrm{~d} t$, where $T$ is the length of the record, $v(t)$ is the ground velocity at time $t, S$ is the wave velocity of the material carrying the wave and $\rho$ is the mass density in the material [27]. In this article, equations are derived for the integral part of this definition and hence do not include the effect of the wave velocity or mass density. Therefore $E_{h}=\int_{0}^{T} v_{h}(t)^{2} \mathrm{~d} t$, where $v_{h}(t)$ is the horizontal ground velocity at time $t$, and $E_{v}=\int_{0}^{T} v_{v}(t)^{2} \mathrm{~d} t$, where $v_{h}(t)$ is the horizontal ground velocity at time $t$. To correctly use the equations derived here, the results must be multiplied by $\frac{1}{4} S \rho$ to obtain the true energy density.

In this article, the estimated ground motions using the equations derived in this study are compared with estimated ground motions using the equations from some commonly cited studies, Boore et al. [9], Campbell and Bozorgnia [15], Ambraseys et al. [7], Ambraseys and Simpson [5], Campbell [14], Chapman [16] and Spudich et al. [28]. As in this study, the comparisons studies mainly use strong-motion records from active tectonic regions, therefore the estimated ground motions from this study and the comparison studies can be directly compared.

All of the comparison studies have included data from earthquakes with all three mechanisms (thrust, strike-slip and normal) except the study of Spudich et al. [28], 
which only includes data from strike-slip and normal faulting earthquakes in extensional regions. However, all the comparison studies, and also this study, include limited numbers of strong-motion records from earthquakes with normal mechanisms.

All of the comparison studies use a significant proportion of near-field records, almost all of which are included within the set of records selected for this study. However, these comparison studies also use many records from the intermediate and far fields, which are of lower engineering significance. Therefore comparisons in estimated ground motions using the equations from the comparison studies (from a mix of near-, intermediate and far-field data) and those derived in this study (from only near-field data) will show the effect of including data of lower engineering significance in sets of records used to derive equations to estimate near-field ground motions.

\subsection{Horizontal PGA, $y=\log \left(a_{h}\right)$}

Figure 2 shows comparison between the horizontal PGA predicted by the new equation given in Table 2 and that predicted by four other widely used equations. Figure 2 shows the following important features.

The new equation predicts much lower accelerations than the equation of Ambraseys et al. [7] especially for large magnitudes, for example for $M_{s}=7.5$ and $d=0 \mathrm{~km}$ the equation of Ambraseys et al. [7] predicts horizontal PGA for soft soil of about $1.4 \mathrm{~g}\left[14 \mathrm{~ms}^{-2}\right]$ compared with the new equation which predicts horizontal PGA for soft soil of about $0.8 \mathrm{~g}\left[8 \mathrm{~ms}^{-2}\right]$. This over-estimation of PGA by the equation of Ambraseys et al. [7] is probably due to the large number of weak 
ground motions in the records used. The new equation predicts similar horizontal PGA to those predicted by the equations of Boore et al. [9] and Campbell [14] reflecting the large number of records from large magnitudes and short distances in their sets. The new equation predicts slightly larger horizontal PGA than the equation of Spudich et al. [28] for extensional regimes, again confirming the finding of Spudich et al. [28] that the strong ground motion in extensional regimes is smaller than that in other tectonic regimes. Spudich et al. [28] use the geometric mean of the two horizontal components rather than the larger horizontal component which could be one factor reducing the predicted accelerations.

The new equation exhibits a lower dependence on magnitude than the equation of Ambraseys et al. [7]. The coefficient of magnitude dependence in the equations derived in this study is 0.202 as compared to 0.266 for the equations of Ambraseys et al. [7]. The equation of Ambraseys et al. [7] was derived using mainly data from small magnitude $\left(M_{s}<6\right)$ earthquakes and so the point source assumption is roughly valid and consequently the equation reflects global fault conditions. For the data used to derive the new equation the point source assumption is not adequate and so the equation reflects the local fault conditions leading to lower magnitude dependence. The magnitude dependence however, is almost identical to that in the equations of Boore et al. [9] and Spudich et al. [28] showing that these equations can be used for ground motion estimation in the near-field. The magnitude dependence of the new equation is larger than that of the equation of Campbell [14] possibly due to the form of the equation adopted by Campbell [14] which allows for distance saturation or because of the distance measure used by Campbell [14] (seismogenic distance) differs from that used here (distance to the surface projection of the rupture plane).

The distance dependence of the new equation is almost identical to that of Boore 
et al. [9] and Spudich et al. [28] and is similar to that of Ambraseys et al. [7] and Campbell [14] showing that the attenuation mechanism that is dominant in the nearfield cannot be determined. This can be seen in Figure 2 because the new curves are almost parallel to the curves derived in the other studies.

The new equation predicts near-field horizontal PGA which is almost independent of site conditions, unlike the equations of Boore et al. [9], Ambraseys et al. [7] and Spudich et al. [28] which show significant dependence of horizontal PGA with site conditions. This can be seen in Figure 2 because the predicted PGAs for all three local site conditions are almost identical (because the site coefficients are small) whereas the predicted PGAs using the equations of Boore et al. [9], Ambraseys et al. [7] and Spudich et al. [28] for different local site conditions vary significantly (because the site coefficients are much larger). The site dependence is also lower than that predicted by the equation of Campbell [14] which allows for site amplifications which are dependent on magnitude and distance. The negligible dependence of near-field horizontal PGA on site conditions shows, as pointed out by Faccioli and Reseńdiz [19], that close to the source, site conditions are less important in determining ground motions than source and path. Also it may indicate non-linear soil behaviour at large strains which occur in the near field of large earthquakes leading to lower soil amplification than for weak ground motions.

The associated standard deviation of the new equation $(\sigma=0.214)$ is slightly smaller than that of the equation of Ambraseys et al. [7] $(\sigma=0.25)$ but similar to that of Boore et al. [9] ( $\sigma=0.205)$, Spudich et al. [28] ( $\sigma=0.204)$ and Campbell [14] (0.169-0.239 dependent on horizontal PGA). This shows that near-field horizontal PGA is not less variable than intermediate-field and far-field horizontal PGA. 


\subsection{Vertical PGA, $y=\log \left(a_{v}\right)$}

A comparison of the new equations for horizontal and vertical PGA shows that the decay with distance of vertical PGA is faster than that of horizontal PGA. This is probably because vertical ground motions are generally of higher frequency than horizontal ground motions (high frequency waves attenuate more rapidly than low frequency waves). Further, the standard deviation of an observation for the new equation for vertical PGA is much larger than that of the new equation for horizontal PGA. Currently, the reason that the estimation of vertical PGA is associated with larger uncertainty than the estimation of horizontal PGA is unknown.

Figure 3 shows comparisons between the peak ground acceleration predicted by the new equation and that predicted by two other widely-used equations. Figure 3 shows the following important features.

The new equation predicts slightly larger vertical PGA than the equation of Ambraseys and Simpson [5] and lower vertical PGA, especially for earthquakes with magnitudes about $M_{s}=6$, than the equation of Campbell [14].

The dependence of vertical PGA on site conditions is similar to that predicted by the equations of Ambraseys and Simpson [5] and Campbell [14] showing that nonlinear soil behaviour at large strains is apparently not as common for vertical ground motions as is for horizontal motions.

As for horizontal PGA the associated standard deviation $(\sigma=0.270)$ is similar to that from the equation of Ambraseys and Simpson [5] $(\sigma=0.25)$ and Campbell [14] $(\sigma=0.231-0.285$ dependent on PGA). 


\subsection{Vertical to horizontal absolute PGA ratio, $y=\log q=\log \left(a_{v} / a_{h}\right)$}

The ratio $q$, of the vertical, $a_{v}$, to the maximum horizontal, $a_{h}$, ground acceleration can be calculated either by combining the two equations which individually predict peak vertical and horizontal accelerations [1], or by performing a regression directly on the ratios of maximum accelerations [4]. Note that whereas Ambraseys and Simpson $[5,6]$ regress directly on the ratio, $a_{v} / a_{h}$, in this study the regression was made on the logarithm of the ratio. This is because the derived equation has a physical interpretation, i.e. exponential dependence on magnitude and decay due to anelastic effects. Also, directly using the ratios of maximum acceleration assumes that the uncertainty associated with this ratio is the same for all levels of ground motion [17, pp. 237-238]. This assumption must be false because otherwise using the standard deviation associated with the equation, to derive predicted ratios for percentiles less than $50 \%$, would lead to the prediction of negative PGA (by definition a positive quantity). Also working directly on the untransformed ratio violates the requirement of the standard least-squares method that the residuals be homoscedastic, i.e. that the residuals are similarly distributed with respect to the predicted value and the independent parameters.

No site coefficients were derived because they do not have a physical meaning, unlike those for horizontal and vertical components separately. This is because for horizontal and vertical ground motions separately the site coefficients are directly connected to the amplifications due to the local site conditions in the direction, i.e. horizontal or vertical, of interest whereas for the ratio of vertical to horizontal motions any site coefficients derived would be due to a combination of amplifications in both the horizontal and vertical directions. Since Ambraseys and Simpson $[5,6]$ find large differences in vertical to horizontal ground motion ratios depend- 
ing on earthquake mechanism, the effect of earthquake mechanism is investigated here. Vertical to horizontal ground motion ratios are more stable than horizontal or vertical ground motions separately, therefore the effect of earthquake mechanism on vertical to horizontal ratios could be considered whereas the limited number of records precludes an investigation of the effect of earthquake mechanism on horizontal and vertical ground motions separately.

Figure 4 shows comparison between the ratio of vertical PGA to horizontal PGA predicted by the equations given in Table 2 and that predicted by equations from two other widely used studies. Figure 4 shows the following important features.

The equations given in Table 2 predict much smaller ratios of vertical to horizontal PGA than do the equations of Ambraseys and Simpson [5] and Campbell and Bozorgnia [15]. The equations of Ambraseys and Simpson [5] predict larger ratios because they use: a) a non-physical model which assumes error is additive rather than multiplicative; b) only records with vertical PGA larger than $0.1 \mathrm{~g}$ thereby biasing the ratios upwards; c) the largest vertical to horizontal PGA ratio (i.e. smallest horizontal component) rather than smallest vertical to horizontal PGA ratio (i.e. largest horizontal component); and d) a small set of records. One reason Campbell and Bozorgnia [15] predict larger ratios is that they use the geometric mean of the two horizontal PGAs rather than the larger horizontal PGA. The larger horizontal PGA is usually found to be about $13 \%$ larger than the geometric mean of the two horizontal PGAs [e.g. 13], therefore when the larger horizontal PGA is used lower vertical to horizontal PGA ratios are found compared to when the geometric mean of the two horizontal PGAs are used.

The equations given in Table 2, the equations of Ambraseys and Simpson [5], and the equations of Campbell and Bozorgnia [15], all predict slightly higher vertical 
to horizontal PGA ratios for strike-slip faulting than thrust faulting.

The equations given in Table 2 show that the commonly used ratios between vertical and horizontal PGA, $q$, of $\frac{1}{2}$ to $\frac{2}{3}$ are reasonable. However, since $q$ represents the ratio of two functions whose maxima occur at different times, its value is a conservative estimate of the combined loading that could occur during an earthquake.

\subsection{Horizontal spectral acceleration, $y=\log \mathrm{SA}_{\mathrm{h}}$}

The coefficients of the horizontal and vertical spectral acceleration equations for $5 \%$ damping at 46 periods between 0.1 and $2 \mathrm{~s}$ and different site conditions are given in Ambraseys and Douglas [3]. The coefficients of the equations for a subset of periods are given in Tables 3 and 4.

Comparing the predicted horizontal spectral accelerations using the new equations with those predicted by four other widely used sets of equations shows a number of important features (Figures 5 to 8 ).

Predicted horizontal spectral accelerations using the new equations are much lower than those predicted by the equations of Ambraseys et al. [7] for large magnitudes $\left(M_{s}>6.5\right)$ especially for very short distances, for example at horizontal natural period $T=0.5 \mathrm{~s}$ the equations of Ambraseys et al. [7] predict a spectral acceleration on soft soil of about $2.3 \mathrm{~g}\left[23 \mathrm{~ms}^{-2}\right]$ whereas using the new equations gives an estimate of about $1.4 \mathrm{~g}\left[14 \mathrm{~ms}^{-2}\right]$. This is similar to the earlier finding for horizontal PGA, i.e. the equations of Ambraseys et al. [7] predicted much larger horizontal PGAs for large magnitude earthquakes than the equations derived in this study. The reason for such large differences for large magnitudes is that the set of records used by Ambraseys et al. [7] is dominated by records from small magnitude earthquakes 
which control the equation. The magnitude dependence for the short period range ( $T<1 \mathrm{~s}$ ) of the near-field equations derived in this study is much less than that in the equations of Ambraseys et al. [7] so the predicted accelerations for large magnitude earthquakes are less. The equations of Boore et al. [9], Campbell [14] and Spudich et al. [28] however, predict horizontal response spectra similar to those given by the new equations because their sets have a large proportion of near-field large-magnitude data and they include terms to account for magnitude saturation which means the predicted spectral accelerations for large magnitudes do not become unrealistically large.

As for horizontal PGA the dependence of spectral acceleration on site conditions is much less in the near-field equations derived in this study than that found in the equations of Ambraseys et al. [7], Boore et al. [9] and Spudich et al. [28] especially in the very short period range $(T<0.2 \mathrm{~s})$. This is probably due to nonlinear soil behaviour due to large strains which would reduce the short period ground motion more than the longer period ground motion, such behaviour is modelled in the equations of Campbell [14].

As for the equation for horizontal PGA the near-field equations derived in this study are associated with similar standard deviations as the equations of Ambraseys et al. [7], Boore et al. [9], Campbell [14] and Spudich et al. [28].

\subsection{Vertical spectral acceleration, $y=\log \mathrm{SA}_{\mathrm{v}}$}

Vertical spectral acceleration for periods less than about $1 \mathrm{~s}$ show faster decay with distance than horizontal spectral accelerations. Unlike the PGA this faster decay cannot be explained by vertical ground motions having the usual higher frequency 
than the horizonal motions because spectral acceleration is a narrow-band measure. As for PGA the standard deviations associated with the near-field equations for vertical spectral acceleration derived here are much higher than those for horizontal spectral acceleration, especially for short periods. For example for $T=0.1 \mathrm{~s}$ the standard deviation for horizontal spectral acceleration is 0.240 whereas for vertical spectral acceleration it is 0.308 .

Soil coefficients for both soft (S) and stiff (A) soil show de-amplification, with respect to rock, at long periods $(T>1 \mathrm{~s})$.

Comparing the predicted vertical spectral accelerations using the new equations with those predicted by two other widely used sets of equations shows a number of important features (Figures 9 and 10).

Predicted vertical spectral accelerations using the new equations are similar to those predicted by the equations of Ambraseys and Simpson [5] and Campbell [14] except in the short period where the equations of Campbell [14] predict higher values, for example for $M_{s}=7.5$ and $d=0 \mathrm{~km}$ the predicted spectral acceleration on rock using the new equations is about $0.8 \mathrm{~g}\left[8 \mathrm{~ms}^{-2}\right]$ whereas on soft rock using the equations of Campbell [14] it is about $1.4 \mathrm{~g}\left[14 \mathrm{~ms}^{-2}\right]$. This difference could be due to the different definition of distance used by Campbell [14] compared to that used here.

The dependence of site conditions on vertical spectral accelerations in the nearfield equations is similar to that found by Ambraseys and Simpson [5] and is much less than that found for horizontal spectral accelerations. The dependence on site conditions is less than that found by Campbell [14] which could be due to the different site categories used or because the vertical spectral acceleration equation of Campbell [14] was derived using equations for horizontal spectral acceleration 
as a base.

Comparing predicted horizontal response spectra (Figures 5 to 8 ) with predicted vertical response spectra (Figures 9 and 10) shows the expected higher frequency of vertical ground motions.

3.6 Horizontal and vertical maximum absolute input energy, $y=\log I_{h}$ and $y=$ $\log I_{v}$

The coefficients of the horizontal and vertical maximum absolute input energy equations for $5 \%$ damping at 46 periods between 0.1 and $2 \mathrm{~s}$ and different site conditions are given in Ambraseys and Douglas [3]. The coefficients of the equations for a subset of periods are given in Tables 5 and 6 .

The maximum absolute input energy, $I$, is defined as $I=\max _{t} \int_{0}^{t}\left[u_{t t}(t)+a(t)\right] v(t) \mathrm{d} t$, where $u_{t t}$ is the response acceleration of the SDOF system, $a(t)$ is the ground acceleration and $v(t)$ is the ground velocity [16]. In the following two sections maximum absolute input energy will simply be referred to as energy.

The new equations show that there is a strong dependence of horizontal maximum absolute input energy on magnitude as is expected because magnitude is roughly related to energy. The coefficients also display a faster decay with distance than spectral acceleration and also a stronger dependence on site conditions. The standard deviations of the equations for horizontal energy are also much higher than those for horizontal spectral acceleration, for example for $T=0.1 \mathrm{~s}$ the associated standard deviation for horizontal spectral acceleration is 0.240 whereas for horizontal maximum absolute input energy it is 0.397 . 
Comparing the predicted energy using the new equations with those predicted by the only other set of attenuation relations [16] for horizontal energy available in the literature (Figure 11) shows the following important features.

Predicted horizontal energies using the new equations are similar to those predicted by the equations of Chapman [16] because many of the records used by Chapman [16] are from large earthquakes and also because the equations allow magnitude saturation. The predicted energies are thus not unrealistically high.

As for horizontal PGA and spectral acceleration there is evidence for nonlinear soil behaviour in the near-field because the dependence of horizontal energy on local site conditions is less than the dependence found by Chapman [16] who uses intermediate-field and far-field records as well as near-field records.

The standard deviations of the near-field equations derived in this study and those of the equations of Chapman [16] are similar.

As for horizontal energy there is a strong dependence of vertical energy on magnitude, a faster decay with distance than for vertical spectral acceleration, greater dependence on local site conditions and also much larger associated standard deviations than the equations for vertical spectral acceleration.

As for vertical spectral acceleration and horizontal spectral acceleration there is much lower dependence of vertical energy on local site conditions than for horizontal energy.

No attenuation relations for the prediction of vertical elastic maximum absolute input energy such as have been derived here (Figure 12) appear to have been published. 


\subsection{Vertical to horizontal spectral ratio (absolute), $y=\log q_{s}=\log \mathrm{SA}_{v} / \mathrm{SA}_{h}$}

There are two methods for finding the predicted vertical to horizontal spectral ratios a) divide the predicted vertical spectral accelerations by the predicted horizontal accelerations or b) regress directly on the spectral ratio to find new attenuation equations for the ratio. The first technique was used by Niazi and Bozorgnia [25], Bozorgnia et al. [10] and Campbell and Bozorgnia [15]. Its main advantage is simplicity. The second technique was used by Feng et al. [20] and Ambraseys and Simpson [5].

Equations to predict the vertical to horizontal spectral ratio, $q_{s}$, were derived assuming magnitude and distance dependence. For some periods, the magnitude coefficient is significant, for some the distance coefficient is significant but for most neither are significant. Therefore it was decided to simply provide the mean of the logarithms and the standard error. Note that even though the magnitude and distance coefficients of the horizontal and vertical spectral acceleration equations are significant at the $5 \%$ level the coefficients for prediction of the ratio are not. Therefore workers who find distance and magnitude dependence of the spectral ratios [e.g. 25, 10, 15] from regressing on the horizontal and vertical spectral ordinates separately may find that this dependence is not significant if the regression is done directly on the ratio.

The coefficients of the vertical to horizontal spectral ratio equations for $5 \%$ damping at 46 periods between 0.1 and $2 \mathrm{~s}$ and different site conditions are given in Ambraseys and Douglas [3]. No site coefficients were derived. The coefficients of the equations for a subset of periods are given in Table 7.

Comparing the predicted vertical to horizontal spectral ratios using the new equa- 
tions with those predicted by two other widely used sets of equations (Figures 13 and 14) show the following important features.

Predicted vertical to horizontal spectral ratios using the new equations are much lower than those predicted using the equations of Ambraseys and Simpson [5] for the same reasons that the predicted vertical to horizontal PGA ratios were lower. However, predicted vertical to horizontal spectral ratios using the new equations and those predicted using the equations of [15] are almost identical except for short periods $(T<0.4 \mathrm{~s})$ where the equations of Campbell and Bozorgnia [15] predict higher ratios; this is similar to the vertical to horizontal PGA ratios.

Predicted vertical to horizontal spectral ratios using the new equations for all source mechanisms, except for normal faulting, are almost identical, as was found by Campbell and Bozorgnia [15]. The apparent differences for different source mechanisms found by Ambraseys and Simpson [5] are probably due to: a) the nonphysical model used by Ambraseys and Simpson [5] which assumes error is additive rather than multiplicative and b) the small set of records. The differences in the vertical to horizontal spectral ratios found for normal faulting earthquakes may not be genuine because only a small number of records (15) from normal faulting earthquakes were used.

\subsection{Vertical to horizontal spectral ratio (simultaneous), $y=\log q_{i}=\log \left(u_{t t, v}\left(t_{\max }\right) / \mathrm{SA}_{\mathrm{h}}\right.$ )}

A major draw-back of the absolute acceleration ratio $q$ or $q_{s}$ for practical purposes is that in an earthquake the maximum ground or response accelerations in the vertical and horizontal direction occur at different times.

Equations to predict the attenuation of vertical to horizontal simultaneous spectral 
ratio were found. This ratio is defined as: $q_{i}=u_{t t, v}\left(t_{\max }\right) / \mathrm{SA}_{\mathrm{h}}$; where $u_{t t, v}(t)$ is the vertical response acceleration and $t_{\max }$ is the time as which the maximum horizontal response acceleration occurs. This ratio gives the size of the vertical accelerations which need to be withstood at the time of the design maximum horizontal acceleration.

The natural period of a structure in the vertical direction is usually different than that in the horizontal direction therefore these ratios, $Q_{i}$, were found for all combinations of vertical and horizontal natural period, i.e. $46 \times 46=2116$.

As for the absolute ratio, for some periods the magnitude coefficient is significant, for some the distance coefficient is significant but for most neither are significant. Therefore it was decided to simply provide the mean of the logarithms and the standard error.

The means and standard deviations for all earthquakes, normal, thrust and strikeslip and European earthquakes separately for $5 \%$ damping at 46 periods between 0.1 and $2 \mathrm{~s}$ and different site conditions are given in Ambraseys and Douglas [3]. The coefficients of the equations for a subset of periods are given in Table 8 .

The predicted $q_{i}$ for all the earthquakes and for each of the separate mechanism (normal, thrust and strike-slip) shows that the ratios are almost the same for each type of faulting except for normal faulting (Figure 15). The results for normal mechanism earthquakes are based on only 15 records; it is difficult to base conclusions on such a small number of records so more records are required from normal earthquakes to check this finding. As Figure 15 shows the simultaneous ratios, $q_{i}$, are much less than the absolute ratios, $q_{s}$, especially for short periods. Also it can be seen that the ratios are roughly independent of period. 
Figure 16 shows the predicted vertical to horizontal simultaneous spectral ratio, $Q_{i}$, for all combinations of $T_{h}$ and $T_{v}$. Figure 17 shows the standard deviations (this is the standard deviations of the logarithms) of the regression.

For short vertical and long horizontal periods the simultaneous ratio, $Q_{i}$, can reach about 0.5 but for most periods the ratio is less than about 0.2 (Figure 16). The standard error is much higher than for the absolute ratio and it is roughly independent of period and equal to about 0.6 (Figure 17). Why there are much higher standard errors at certain, seemingly random, combinations of periods is not known.

3.9 Vertical to horizontal maximum absolute input energy ratio, $y=\log q_{e}=$ $\log I_{v} / I_{h}$

The means and standard deviations of $\log q_{e}$ for all earthquakes, normal, thrust and strike-slip and European earthquakes separately for $5 \%$ damping at 46 periods between 0.1 and $2 \mathrm{~s}$ and different site conditions are given in Ambraseys and Douglas [3]. The coefficients of the equations for a subset of periods are given in Table 9.

Figure 18 shows the predicted ratio, $q_{e}$, for all earthquakes and considering the three source mechanisms separately. As for the response spectral equations only predicted ratios for normal mechanism earthquakes are different than those for other types of faulting, although this may be due to a small number of records from normal earthquakes. Figure 18 shows that even for short periods vertical ground motions contain much less energy than horizontal ground motions. 


\section{Conclusions}

The ratio of the maximum peak ground acceleration to maximum horizontal in an earthquake, which individually occur at different instants, may exceed one, but their ratio $q$ falls off with distance. Due to lack of data for strike-slip and normal events the magnitude and distance dependence of the ratio, $q$, cannot be found but the mean ratios are 0.73 and 0.61 respectively, hence they are close to the commonly accepted ratio of $\frac{2}{3}$. The complete near-field dataset and the thrust subset show significant distance dependence, the ratios decrease with distance, and the predicted ratios also are close to $\frac{2}{3}$. Note, that the maximum values of the vertical and horizontal peak acceleration in this ratio occur at different times in an earthquake.

The spectral response of the vertical acceleration and the attenuation of its spectral ordinates with magnitude and distance differ in amplitude and shape from those of the horizontal.

The ratio $q_{s}$ of the maximum vertical spectral response to the horizontal may exceed one at very short periods $(<0.15 \mathrm{~s})$, but falls off rapidly with period reaching a value of about 0.5 for long periods. Note that maximum spectral values of this ratio occur at different times but for the same response period in both horizontal and vertical direction $\left(T_{h}=T_{v}\right)$.

The ratio of the vertical spectral response that occurs at the time of the maximum horizontal response $q_{i}$ does not exceed 0.2 and is insensitive to magnitude and distance. Note that in this case the response period in the horizontal and vertical directions are equal.

The acceleration ratio $q\left(T_{h}, T_{v}\right)$ for response periods $T_{h}$ and $T_{v}$ which are not equal, 
remains smaller than 0.3 . The exception is for the rather unrealistic combination of very short vertical periods $(0.1 \mathrm{~s})$ with very long horizontal $(>1.0 \mathrm{~s})$ for which $q$ may reach 0.6.

For elastic structures the energy input from the vertical component is a small fraction of the energy input due to the horizontal.

\section{Acknowledgements}

We would like to thank all the colleagues who gave us their views regarding the effect of vertical motion on design. Also, we would like to thank Drs. K. Simpson, M. Srbulov, M. Free and S.K. Sarma and P. Smit for their help in this research which was supported by EPSRC. In addition, critical reviews by two anonymous reviewers were helpful and lead to significant improvements to the article.

\section{References}

[1] Abrahamson, N. A., Litehiser, J. J., Jun 1989. Attenuation of vertical peak acceleration. Bulletin of the Seismological Society of America 79 (3), 549580.

[2] Abrahamson, N. A., Somerville, P. G., Feb 1996. Effects of the hanging wall and footwall on ground motions recorded during the Northridge earthquake. Bulletin of the Seismological Society of America 86 (1B), S93-S99.

[3] Ambraseys, N., Douglas, J., Aug 2000. Reappraisal of the effect of vertical ground motions on response. ESEE Report 00-4, Department of Civil and Environmental Engineering, Imperial College, London.

[4] Ambraseys, N. N., Bommer, J. J., 1991. The attenuation of ground acceler- 
ations in Europe. Earthquake Engineering and Structural Dynamics 20 (12), 1179-1202.

[5] Ambraseys, N. N., Simpson, K. A., 1996. Prediction of vertical response spectra in Europe. Earthquake Engineering and Structural Dynamics 25 (4), 401412.

[6] Ambraseys, N. N., Simpson, K. A., 1997. The effect of vertical acceleration on horizontal response. ESEE report, Department of Civil and Environmental Engineering, Imperial College, London.

[7] Ambraseys, N. N., Simpson, K. A., Bommer, J. J., 1996. Prediction of horizontal response spectra in Europe. Earthquake Engineering and Structural Dynamics 25 (4), 371-400.

[8] Benavent-Climent, A., Pujade, L. G., Lòpez-Almansa, F., 2002. Design energy input spectra for moderate-seismicity regions. Earthquake Engineering and Structural Dynamics 31, 1151-1172.

[9] Boore, D. M., Joyner, W. B., Fumal, T. E., 1993. Estimation of response spectra and peak accelerations from western North American earthquakes: An interim report. Open-File Report 93-509, U.S. Geological Survey.

[10] Bozorgnia, Y., Campbell, K. W., Niazi, M., 2000. Observed spectral characteristics of vertical ground motion recorded during worldwide earthquakes from 1957 to 1995. In: Proceedings of Twelfth World Conference on Earthquake Engineering. Paper No. 2671.

[11] Brillinger, D. R., Preisler, H. K., 1984. An exploratory analysis of the JoynerBoore attenuation data. Bulletin of the Seismological Society of America 74 (4), 1441-1450.

[12] Brillinger, D. R., Preisler, H. K., 1985. Further analysis of the Joyner-Boore attenuation data. Bulletin of the Seismological Society of America 75 (2), $611-614$. 
[13] Campbell, K. W., Dec 1981. Near-source attenuation of peak horizontal acceleration. Bulletin of the Seismological Society of America 71 (6), 2039-2070.

[14] Campbell, K. W., Jan/Feb 1997. Empirical near-source attenuation relationships for horizontal and vertical components of peak ground acceleration, peak ground velocity, and pseudo-absolute acceleration response spectra. Seismological Research Letters 68 (1), 154-179.

[15] Campbell, K. W., Bozorgnia, Y., Nov 2000. New empirical models for predicting near-source horizontal, vertical, and $V / H$ response spectra: Implications for design. In: Proceedings of the Sixth International Conference on Seismic Zonation.

[16] Chapman, M. C., Nov 1999. On the use of elastic input energy for seismic hazard analysis. Earthquake Spectra 15 (4), 607-635.

[17] Draper, N. R., Smith, H., 1981. Applied Regression Analysis, 2nd Edition. John Wiley \& Sons.

[18] Ekström, G., Dziewonski, A. M., Mar 1988. Evidence of bias in estimations of earthquake size. Nature 332, 319-323.

[19] Faccioli, E., Reseńdiz, D., 1976. Soil dynamics: Behavior including liquefaction. In: Lomnitz, C., Rosenblueth, E. (Eds.), Seismic Risk and Engineering Decisions. Elsevier Scientific Publishing Company, Ch. 4, pp. 71-139.

[20] Feng, D., Theofanopoulos, N., Watabe, M., 1988. Consideration on the design velocity response spectra along the principal axes. In: Proceedings of Ninth World Conference on Earthquake Engineering. Vol. II. pp. 855-860.

[21] Fukushima, Y., Tanaka, T., 1990. A new attenuation relation for peak horizontal acceleration of strong earthquake ground motion in Japan. Bulletin of the Seismological Society of America 80 (4), 757-783.

[22] Fukushima, Y., Tanaka, T., Kataoka, S., 1988. A new attenuation relationship for peak ground acceleration derived from strong-motion accelerograms. In: 
Proceedings of Ninth World Conference on Earthquake Engineering. Vol. II. pp. $343-348$.

[23] Joyner, W. B., Boore, D. M., Dec 1981. Peak horizontal acceleration and velocity from strong-motion records including records from the 1979 Imperial Valley, California, earthquake. Bulletin of the Seismological Society of America 71 (6), 2011-2038.

[24] Menu, J. M. H., 1986. Engineering study of near-field earthquake strongmotions. Ph.D. thesis, University of London.

[25] Niazi, M., Bozorgnia, Y., 1992. Behaviour of near-source vertical and horizontal response spectra at SMART-1 array, Taiwan. Earthquake Engineering and Structural Dynamics 21, 37-50.

[26] Şafak, E., 2000. Characterization of seismic hazard and structural response by energy flux. Soil Dynamics and Earthquake Engineering 20, 39-43.

[27] Sarma, S. K., 1971. Energy flux of strong earthquakes. Tectonophysics 11, $159-173$.

[28] Spudich, P., Joyner, W. B., Lindh, A. G., Boore, D. M., Margaris, B. M., Fletcher, J. B., Oct 1999. SEA99: A revised ground motion prediction relation for use in extensional tectonic regimes. Bulletin of the Seismological Society of America 89 (5), 1156-1170. 
Table 1

Summary of distribution of data in the set of records used with respect to geographical location, faulting mechanism and site classification. Note, percentages do not add up to $100 \%$ because of rounding.

\begin{tabular}{lcl}
\hline Category & Number of records & Percentage of total \\
\hline \multicolumn{3}{c}{ Geographical location } \\
Western North America & 133 & 72 \\
Europe and Middle East & 40 & 22 \\
Other regions of the world & 13 & 7 \\
\hline \multicolumn{3}{c}{ Earthquake mechanism } \\
Thrust & 98 & 53 \\
Strike-slip & 72 & 39 \\
Normal & 16 & 9 \\
\hline & Site classification & \\
Very soft soil (L) & 4 & 2 \\
Soft soil (S) & 83 & 45 \\
Stiff soil (A) & 68 & 37 \\
Rock (R) & 23 & 12 \\
Unknown & 8 & 4 \\
\hline
\end{tabular}


Table 2

Coefficients of equations for estimation of horizontal peak ground acceleration $\left(a_{h}\right)$, vertical peak ground acceleration $\left(a_{v}\right)$, vertical to horizontal absolute peak ground acceleration ratio $(q)$, vertical to horizontal simultaneous peak ground acceleration ratio $\left(q_{\text {sim }}\right)$, horizontal energy density $\left(E_{h}\right)$, vertical energy density $\left(E_{v}\right)$ and vertical to horizontal energy density ratio $\left(q_{E}\right)$. Column labelled 'Sig. $b_{A}$ ?' states whether the $b_{A}$ coefficient is significant at the $5 \%$ significance level, 'Sig. $b_{S}$ ?' states whether the $b_{S}$ coefficient is significant at the $5 \%$ significance level and $\sigma$ is the standard deviation of the equation.

\begin{tabular}{llllllllll}
\hline \multicolumn{2}{c}{ Parameter } & $b_{1}$ & $b_{2}$ & $b_{3}$ & $b_{A}$ & $b_{S}$ & Sig. $b_{A} ?$ & Sig. $b_{S} ?$ & $\sigma$ \\
\hline $\log \left(a_{h}\right)$ & & -0.659 & 0.202 & -0.0238 & 0.020 & 0.029 & No & No & 0.214 \\
\hline $\log \left(a_{v}\right)$ & & -0.959 & 0.226 & -0.0312 & 0.024 & 0.075 & No & No & 0.270 \\
\hline $\log (q)$ & All & -0.119 & & -0.00799 & & & & & 0.21 \\
& Normal & -0.216 & & & & & & & 0.13 \\
& Thrust & -0.103 & & -0.0133 & & & & & 0.17 \\
& Strike-slip & -0.138 & & & & & & & 0.25 \\
& European & -1.11 & 0.132 & & & & & & 0.16 \\
\hline $\log \left(q_{\text {sim }}\right)$ & All & -0.996 & & & & & & & 0.56 \\
& Normal & -0.830 & & & & & & & 0.44 \\
& Thrust & -1.04 & & & & & & & 0.58 \\
& Strike-slip & -0.978 & & & & & & & 0.56 \\
& European & -0.939 & & & & & & & 0.58 \\
\hline $\log \left(E_{h}\right)$ & & -3.11 & 0.937 & -0.0567 & 0.180 & 0.417 & No & Yes & 0.419 \\
\hline $\log \left(E_{v}\right)$ & & -3.88 & 0.969 & -0.0527 & 0.000 & 0.111 & No & No & 0.422 \\
\hline $\log \left(q_{E}\right)$ & All & -0.756 & & & & & & & 0.34 \\
& Normal & -0.540 & & & & & & & 0.25 \\
& Thrust & -0.762 & & & & & & & 0.34 \\
& Strike-slip & -0.795 & & & & & & & 0.35 \\
& European & -0.632 & & & & & & & \\
\hline
\end{tabular}


Table 3

Coefficients of horizontal spectral acceleration relations. $T$ is natural period. Soil coefficients labelled with $\left(^{*}\right)$ are significant at the $5 \%$ level.

\begin{tabular}{l|clclll}
\hline$T$ & $b_{1}$ & $b_{2}$ & $b_{3}$ & $b_{A}$ & $b_{S}$ & $\sigma$ \\
\hline 0.10 & 0.028 & 0.143 & -0.0238 & -0.042 & -0.014 & 0.240 \\
0.15 & 0.110 & 0.135 & -0.0189 & 0.001 & 0.001 & 0.251 \\
0.20 & -0.182 & 0.175 & -0.0164 & 0.006 & 0.049 & 0.251 \\
0.30 & -0.554 & 0.231 & -0.0251 & 0.057 & $0.117\left(^{*}\right)$ & 0.251 \\
0.40 & -0.714 & 0.246 & -0.0263 & 0.086 & $0.119\left(^{*}\right)$ & 0.256 \\
0.50 & -0.992 & 0.275 & -0.0252 & 0.110 & $0.178\left(^{*}\right)$ & 0.253 \\
0.75 & -1.182 & 0.291 & -0.0352 & 0.113 & $0.220\left(^{*}\right)$ & 0.264 \\
1.00 & -1.726 & 0.347 & -0.0307 & $0.153\left(^{*}\right)$ & $0.220\left(^{*}\right)$ & 0.272 \\
1.50 & -2.904 & 0.492 & -0.0298 & 0.128 & $0.225\left(^{*}\right)$ & 0.276 \\
2.00 & -3.380 & 0.543 & -0.0326 & 0.098 & $0.215\left(^{*}\right)$ & 0.262 \\
\hline
\end{tabular}

Table 4

Coefficients of vertical spectral acceleration relations. $T$ is natural period. Soil coefficients labelled with (*) are significant at the $5 \%$ level.

\begin{tabular}{l|clclll}
\hline$T$ & $b_{1}$ & $b_{2}$ & $b_{3}$ & $b_{A}$ & $b_{S}$ & $\sigma$ \\
\hline 0.10 & -0.513 & 0.209 & -0.0287 & 0.025 & 0.113 & 0.308 \\
0.15 & -0.706 & 0.226 & -0.0268 & 0.070 & 0.118 & 0.287 \\
0.20 & -0.858 & 0.241 & -0.0275 & 0.056 & 0.066 & 0.282 \\
0.30 & -1.106 & 0.261 & -0.0265 & 0.050 & 0.012 & 0.256 \\
0.40 & -1.547 & 0.309 & -0.0292 & $0.108\left(^{*}\right)$ & 0.043 & 0.255 \\
0.50 & -1.524 & 0.302 & -0.0325 & 0.081 & 0.015 & 0.243 \\
0.75 & -1.855 & 0.337 & -0.0364 & 0.057 & -0.006 & 0.258 \\
1.00 & -2.294 & 0.384 & -0.0335 & 0.028 & 0.021 & 0.259 \\
1.50 & -2.981 & 0.466 & -0.0292 & -0.072 & -0.055 & 0.285 \\
2.00 & -3.680 & 0.543 & -0.0304 & -0.042 & 0.004 & 0.290 \\
\hline
\end{tabular}


Table 5

Coefficients of horizontal maximum absolute input energy relations. $T$ is natural period.

Soil coefficients labelled with (*) are significant at the $5 \%$ level.

\begin{tabular}{l|clllll}
\hline$T$ & $b_{1}$ & $b_{2}$ & $b_{3}$ & $b_{A}$ & $b_{S}$ & $\sigma$ \\
\hline 0.10 & -0.874 & 0.613 & -0.0593 & 0.041 & 0.169 & 0.397 \\
0.15 & -0.181 & 0.529 & -0.0492 & 0.082 & 0.133 & 0.413 \\
0.20 & -0.156 & 0.539 & -0.0426 & 0.052 & 0.171 & 0.412 \\
0.30 & -0.381 & 0.600 & -0.0504 & 0.120 & $0.271\left(^{*}\right)$ & 0.435 \\
0.40 & -0.429 & 0.617 & -0.0512 & 0.195 & $0.257\left(^{*}\right)$ & 0.458 \\
0.50 & -0.743 & 0.662 & -0.0471 & 0.215 & $0.344\left(^{*}\right)$ & 0.478 \\
0.75 & -0.519 & 0.639 & -0.0640 & 0.243 & $0.460\left(^{*}\right)$ & 0.499 \\
1.00 & -1.291 & 0.740 & -0.0560 & $0.296\left(^{*}\right)$ & $0.440\left(^{*}\right)$ & 0.523 \\
1.50 & -3.198 & 1.005 & -0.0509 & 0.262 & $0.487\left(^{*}\right)$ & 0.502 \\
2.00 & -3.700 & 1.074 & -0.0593 & 0.206 & $0.464\left(^{*}\right)$ & 0.487 \\
\hline
\end{tabular}

Table 6

Coefficients of vertical maximum absolute input energy relations. $T$ is natural period. Soil coefficients labelled with (*) are significant at the $5 \%$ level.

\begin{tabular}{l|clcccc}
\hline$T$ & $b_{1}$ & $b_{2}$ & $b_{3}$ & $b_{A}$ & \multicolumn{1}{l}{$b_{S}$} & $\sigma$ \\
\hline 0.10 & -0.986 & 0.572 & -0.0585 & -0.009 & 0.177 & 0.477 \\
0.15 & -0.928 & 0.576 & -0.0522 & 0.093 & 0.194 & 0.505 \\
0.20 & -1.096 & 0.606 & -0.0508 & 0.112 & 0.154 & 0.499 \\
0.30 & -1.327 & 0.644 & -0.0497 & 0.088 & 0.064 & 0.457 \\
0.40 & -1.673 & 0.689 & -0.0528 & 0.184 & 0.122 & 0.465 \\
0.50 & -1.532 & 0.675 & -0.0571 & 0.177 & 0.098 & 0.457 \\
0.75 & -1.589 & 0.699 & -0.0652 & 0.144 & 0.067 & 0.476 \\
1.00 & -2.044 & 0.762 & -0.0600 & 0.090 & 0.105 & 0.488 \\
1.50 & -3.177 & 0.932 & -0.0516 & -0.079 & -0.010 & 0.521 \\
2.00 & -3.997 & 1.042 & -0.0582 & -0.070 & 0.077 & 0.528 \\
\hline
\end{tabular}




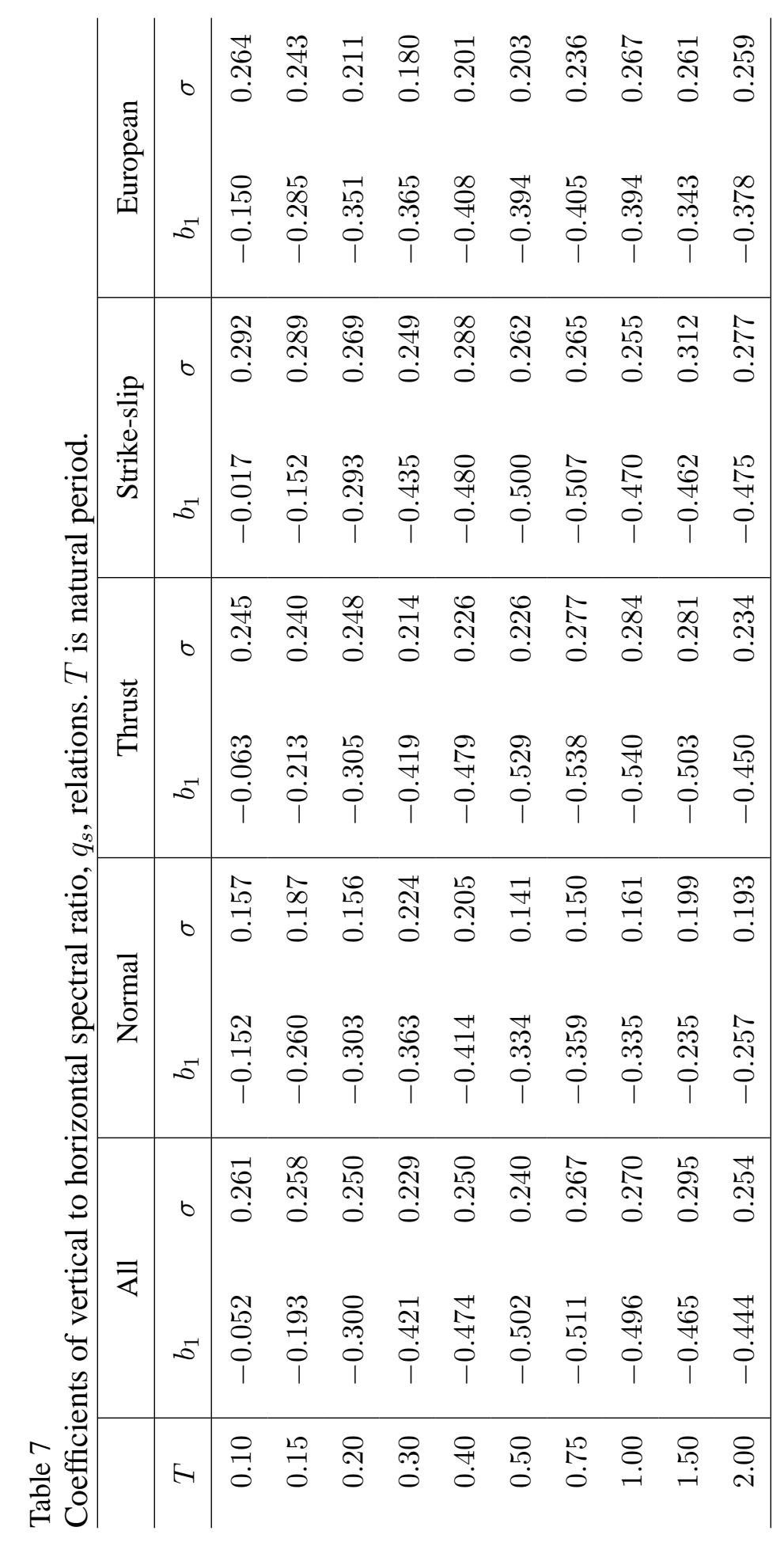




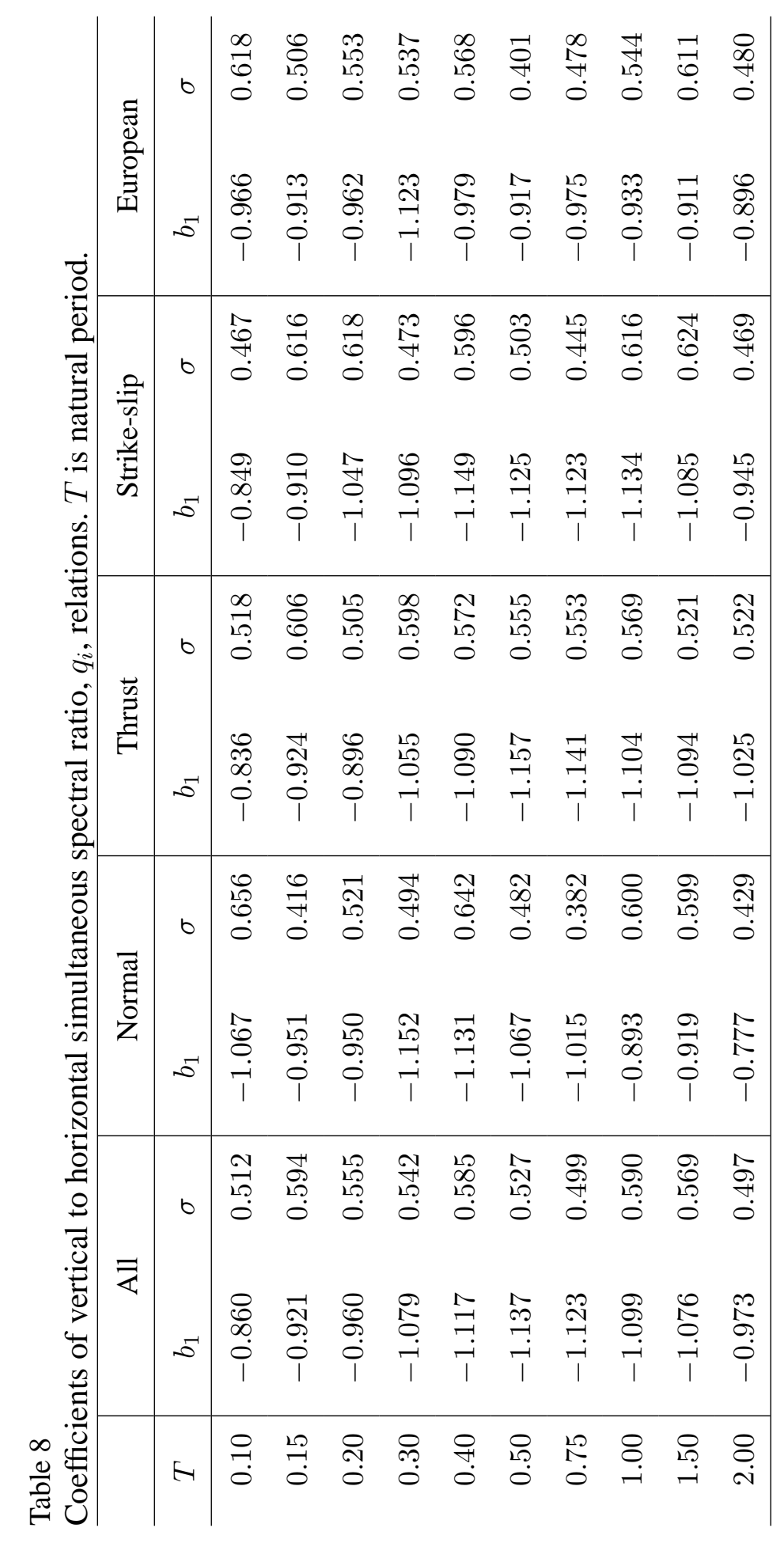




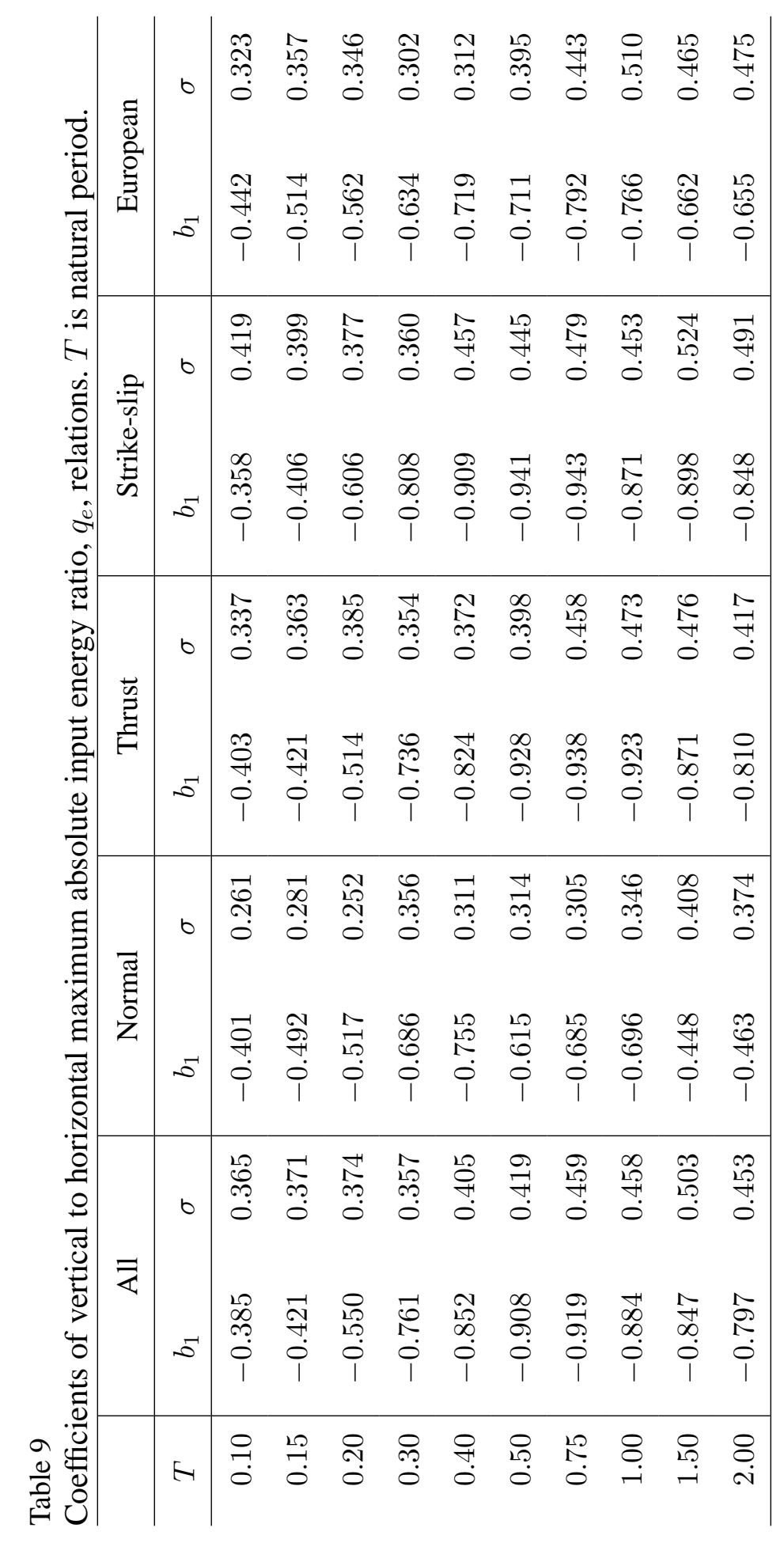


Figure captions

(1) Distribution of all records in new near-field dataset with respect to magnitude and distance.

(2) Comparison of predicted horizontal PGA (new equation, solid lines) and that predicted using the equations of Ambraseys et al. [7], Boore et al. [9], Campbell [14] and Spudich et al. [28] (dashed lines) for $M_{s}=6,7.5$ (corresponding to $M_{w}=6.1,7.5$ using equation (2) of Ekström and Dziewonski [18]) for different site categories. The equation of Campbell [14] is plotted for strike-slip faulting assuming a vertical rupture plane and depth to top of seismogenic zone of $3 \mathrm{~km}$. Note the new equation is converted to $\mathrm{g}$ when plotted.

(a) Comparison with Ambraseys et al. (1996) (dashed lines). S is for $180 \leq$ $V_{\mathrm{s}, 30}<360 \mathrm{~ms}^{-1}$ (soft soil) sites, A is for $360 \leq V_{\mathrm{s}, 30}<750 \mathrm{~ms}^{-1}$ (stiff soil) sites and $\mathrm{R}$ is for $V_{\mathrm{s}, 30} \geq 750 \mathrm{~ms}^{-1}$ (rock) sites.

(b) Comparison with Boore et al. (1993) (larger component) (dashed lines). A is for $V_{\mathrm{s}, 30} \geq 750 \mathrm{~ms}^{-1}$ sites, $\mathrm{B}$ is for $360 \leq V_{\mathrm{s}, 30}<750 \mathrm{~ms}^{-1}$ sites and $\mathrm{C}$ is for $180 \leq V_{\mathrm{s}, 30}<360 \mathrm{~ms}^{-1}$ sites.

(c) Comparison with Campbell (1997) (dashed lines). FS is for alluvial or firm soil sites, SR is for soft rock sites and HR is for hard rock sites.

(d) Comparison with Spudich et al. (1999) (dashed lines).

(3) Comparison of predicted vertical PGA (new equation, solid lines) and that predicted using the equations of Ambraseys and Simpson [5] and Campbell [14] (dashed lines) for $M_{s}=6,7.5$ (corresponding to $M_{w}=6.1,7.5$ using equation (2) of Ekström and Dziewonski [18]) for different site categories. The equation of Campbell [14] is plotted for strike-slip faulting assuming a vertical rupture plane and depth to top of seismogenic zone of $3 \mathrm{~km}$. Note the new equation is converted to $\mathrm{g}$ when plotted. 
(a) Comparison with Ambraseys \& Simpson (1996) (dashed lines). S is for $180 \leq V_{\mathrm{s}, 30}<360 \mathrm{~ms}^{-1}$ (soft soil) sites, $\mathrm{A}$ is for $360 \leq V_{\mathrm{s}, 30}<750 \mathrm{~ms}^{-1}$ (stiff soil) sites and $\mathrm{R}$ is for $V_{\mathrm{s}, 30} \geq 750 \mathrm{~ms}^{-1}$ (rock) sites

(b) Comparison with Campbell (1997) (dashed lines). FS is for alluvial or firm soil sites, SR is for soft rock sites and HR is for hard rock sites.

(4) Comparison of predicted ratios of vertical PGA to horizontal PGA (Table 2, solid lines) and those predicted using the equations of Ambraseys and Simpson [5] and Campbell and Bozorgnia [15] (dashed lines) for $M_{s}=6,7.5$ (corresponding to $M_{w}=6.1,7.5$ using equation (2) of Ekström and Dziewonski [18]) for different source mechanisms. The equation of Campbell and Bozorgnia [15], for the ratio of uncorrected vertical PGA to horizontal PGA, is plotted for Holocene soil assuming a vertical rupture plane and depth to top of seismogenic zone of $3 \mathrm{~km}$.

(a) Comparison with Ambraseys \& Simpson (1996) (dashed lines).

(b) Comparison with Campbell \& Bozorgnia (2000) (dashed lines).

(5) Comparison of predicted horizontal response spectra using the new equations (solid lines) and those predicted using the equations of Ambraseys et al. [7] (dashed lines) for $M_{s}=6$ and $d=15 \mathrm{~km}$ and for $M_{s}=7.5$ and $d=5 \mathrm{~km}$ for different site categories. $\mathrm{S}$ is for $180 \leq V_{\mathrm{s}, 30}<360 \mathrm{~ms}^{-1}$ (soft soil) sites, A is for $360 \leq V_{\mathrm{s}, 30}<750 \mathrm{~ms}^{-1}$ (stiff soil) sites and $\mathrm{R}$ is for $V_{\mathrm{s}, 30} \geq 750 \mathrm{~ms}^{-1}$ (rock) sites.

(a) $M_{s}=6, d=15 \mathrm{~km}$.

(b) $M_{s}=7.5, d=5 \mathrm{~km}$.

(6) Comparison of predicted horizontal response spectra using the new equations(solid lines) and those predicted using the equations of Boore et al. [9] (dashed lines) for $M_{s}=6$ (corresponding to $M_{w}=6.1$ using equation (2) of Ekström and Dziewonski [18]) and $d=15 \mathrm{~km}$ and for $M_{s}=7.5$ (corre- 
sponding to $M_{w}=7.5$ using equation (2) of Ekström and Dziewonski [18]) and $d=5 \mathrm{~km}$ for different site categories. Boore et al. [9] equations give pseudo-acceleration response spectra. A is for $V_{\mathrm{s}, 30} \geq 750 \mathrm{~ms}^{-1}$ sites, $\mathrm{B}$ is for $360 \leq V_{\mathrm{s}, 30}<750 \mathrm{~ms}^{-1}$ sites and $\mathrm{C}$ is for $180 \leq V_{\mathrm{s}, 30}<360 \mathrm{~ms}^{-1}$ sites.

(a) $M_{s}=6\left(M_{w}=6.1\right), d=15 \mathrm{~km}$.

(b) $M_{s}=7.5\left(M_{w}=7.5\right), d=5 \mathrm{~km}$.

(7) Comparison of predicted horizontal response spectra using the new equations(solid lines) and those predicted using the equations of Campbell [14] (dashed lines) for $M_{s}=6$ (corresponding to $M_{w}=6.1$ using equation (2) of Ekström and Dziewonski [18]) and $d=15 \mathrm{~km}$ and for $M_{s}=7.5$ (corresponding to $M_{w}=7.5$ using equation (2) of Ekström and Dziewonski [18]) and $d=5 \mathrm{~km}$ for different site categories. The equation of Campbell [14] is plotted for strike-slip faulting assuming a vertical rupture plane and depth to top of seismogenic zone of $3 \mathrm{~km}$. FS is firm soil, SR is soft rock and HR is hard rock. For firm soil and soft rock a depth to basement rock of $2 \mathrm{~km}$ is assumed. Campbell [14] equations give pseudo-acceleration response spectra.

(a) $M_{s}=6\left(M_{w}=6.1\right), d=15 \mathrm{~km}$.

(b) $M_{s}=7.5\left(M_{w}=7.5\right), d=5 \mathrm{~km}$.

(8) Comparison of predicted horizontal response spectra using the new equations (solid lines) and those predicted using the equations of Spudich et al. [28] (dashed lines) for $M_{s}=6$ (corresponding to $M_{w}=6.1$ using equation (2) of Ekström and Dziewonski [18]) and $d=15 \mathrm{~km}$ and for $M_{s}=7.5$ (corresponding to $M_{w}=7.5$ using equation (2) of Ekström and Dziewonski [18]) and $d=5 \mathrm{~km}$ for different site categories. Spudich et al. [28] equations give pseudo-acceleration response spectra.

(a) $M_{s}=6\left(M_{w}=6.1\right), d=15 \mathrm{~km}$.

(b) $M_{s}=7.5\left(M_{w}=7.5\right), d=5 \mathrm{~km}$. 
(9) Comparison of predicted vertical response spectra using the new equations (solid lines) and those predicted using the equations of Ambraseys and Simpson [5] (dashed lines) for $M_{s}=6$ and $d=15 \mathrm{~km}$ and for $M_{s}=7.5$ and $d=5 \mathrm{~km}$ for different site categories. $\mathrm{S}$ is for $180 \leq V_{\mathrm{s}, 30}<360 \mathrm{~ms}^{-1}$ (soft soil) sites, $\mathrm{A}$ is for $360 \leq V_{\mathrm{s}, 30}<750 \mathrm{~ms}^{-1}$ (stiff soil) sites and $\mathrm{R}$ is for $V_{\mathrm{s}, 30} \geq 750 \mathrm{~ms}^{-1}$ (rock) sites.

(a) $M_{s}=6, d=15 \mathrm{~km}$.

(b) $M_{s}=7.5, d=5 \mathrm{~km}$.

(10) Comparison of predicted vertical response spectra using the new equations (solid lines) and those predicted using the equations of Campbell [14] (dashed lines) for $M_{s}=6$ (corresponding to $M_{w}=6.1$ using equation (2) of Ekström and Dziewonski [18]) and $d=15 \mathrm{~km}$ and for $M_{s}=7.5$ (corresponding to $M_{w}=7.5$ using equation (2) of Ekström and Dziewonski [18]) and $d=$ $5 \mathrm{~km}$ for different site categories. The equation of Campbell [14] is plotted for strike-slip faulting assuming a vertical rupture plane and depth to top of seismogenic zone of $3 \mathrm{~km}$. FS is firm soil, SR is soft rock and HR is hard rock. For firm soil and soft rock a depth to basement rock of $2 \mathrm{~km}$ is assumed. Campbell [14] equations give pseudo-acceleration response spectra.

(a) $M_{s}=6\left(M_{w}=6.1\right), d=15 \mathrm{~km}$.

(b) $M_{s}=7.5\left(M_{w}=7.5\right), d=5 \mathrm{~km}$.

(11) Comparison of predicted absolute unit input energy spectra using the new equations (solid lines) and those predicted using the equations of Chapman [16] (dashed lines) for $M_{s}=6$ (corresponding to $M_{w}=6.1$ using equation (2) of Ekström and Dziewonski [18]) and $d=15 \mathrm{~km}$ and for $M_{s}=7.5$ (corresponding to $M_{w}=7.5$ using equation (2) of Ekström and Dziewonski [18]) and $d=5 \mathrm{~km}$ for different site categories. Chapman [16] equations are converted from absolute input energy equivalent velocity, $V_{\text {ea. }}$ A $\&$ B are for 
$V_{\mathrm{s}, 30} \geq 760 \mathrm{~ms}^{-1}$ sites, $\mathrm{C}$ is for $360 \leq V_{\mathrm{s}, 30}<760 \mathrm{~ms}^{-1}$ sites and $\mathrm{D}$ is for $180 \leq V_{\mathrm{s}, 30}<360 \mathrm{~ms}^{-1}$ sites.

(a) $M_{s}=6\left(M_{w}=6.1\right), d=15 \mathrm{~km}$.

(b) $M_{s}=7.5\left(M_{w}=7.5\right), d=5 \mathrm{~km}$.

(12) Predicted vertical maximum absolute unit input energy spectra using the new equations for $M_{s}=6$ and $d=15 \mathrm{~km}$ and for $M_{s}=7.5$ and $d=5 \mathrm{~km}$ for different site categories.

(a) $M_{s}=6, d=15 \mathrm{~km}$.

(b) $M_{s}=7.5, d=5 \mathrm{~km}$.

(13) Comparison of predicted vertical to horizontal spectral ratios using the new equations (solid lines) and those predicted using the equations of Ambraseys and Simpson [5] (dashed lines) for $M_{s}=6$ and $d=15 \mathrm{~km}$ and for $M_{s}=7.5$ and $d=5 \mathrm{~km}$ for different source mechanisms.

(a) $M_{s}=6, d=15 \mathrm{~km}$.

(b) $M_{s}=7.5, d=5 \mathrm{~km}$.

(14) Comparison of predicted vertical to horizontal spectral ratios using the new equations (solid lines) and those predicted using the equations of Campbell and Bozorgnia [15] (dashed lines) for $M_{s}=6$ (corresponding to $M_{w}=6.1$ using equation (2) of Ekström and Dziewonski [18]) and $d=15 \mathrm{~km}$ and for $M_{s}=7.5$ (corresponding to $M_{w}=7.5$ using equation (2) of Ekström and Dziewonski [18]) and $d=5 \mathrm{~km}$ for different source mechanisms. The equation of Campbell and Bozorgnia [15], for the ratio of uncorrected vertical PGA to horizontal PGA, is plotted for Holocene soil assuming a vertical rupture plane and depth to top of seismogenic zone of $3 \mathrm{~km}$.

(a) $M_{s}=6\left(M_{w}=6.1\right), d=15 \mathrm{~km}$.

(b) $M_{s}=7.5\left(M_{w}=7.5\right), d=5 \mathrm{~km}$. 
(15) Predicted vertical to horizontal spectral ratio, $q_{s}=\mathrm{SA}_{\mathrm{v}} / \mathrm{SA}_{\mathrm{h}}$ (top set of curves) and simultaneous ratio, $q_{i}=R_{v}\left(t_{\max }\right) / \mathrm{SA}_{\mathrm{h}}$ for different types of faulting. All earthquakes (solid line), normal (dashed line), thrust (dotted line) and strike-slip (dash-dotted line).

(16) Predicted vertical to horizontal simultaneous spectral ratio, $Q_{i}=R_{v}\left(t_{\max }\right) / \mathrm{SA}_{\mathrm{h}}$.

(17) Standard error of prediction, $\sigma$, of vertical to horizontal simultaneous spectral ratio, $Q_{i}=R_{v}\left(t_{\max }\right) / \mathrm{SA}_{\mathrm{h}}$.

(18) Predicted vertical to horizontal maximum absolute input energy ratio, $q_{e}=$ $I_{v} / I_{h}$ for different types of faulting. All earthquakes (solid line), normal (dashed line), thrust (dotted line) and strike-slip (dash-dotted line). 


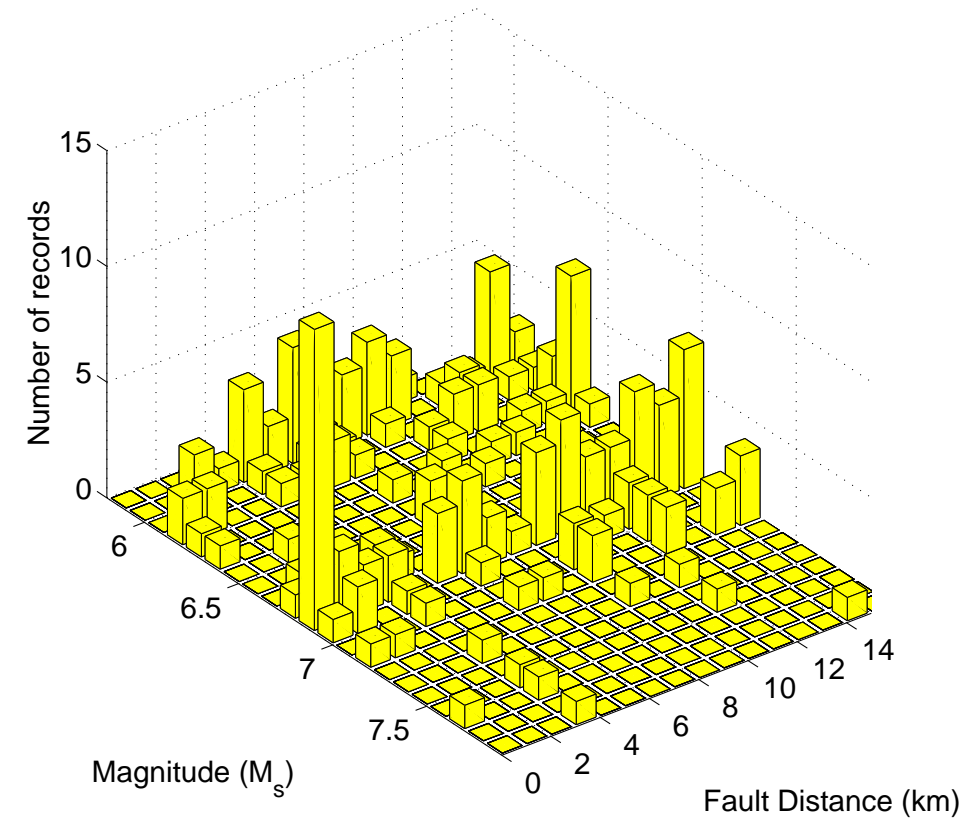

Fig. 1. 


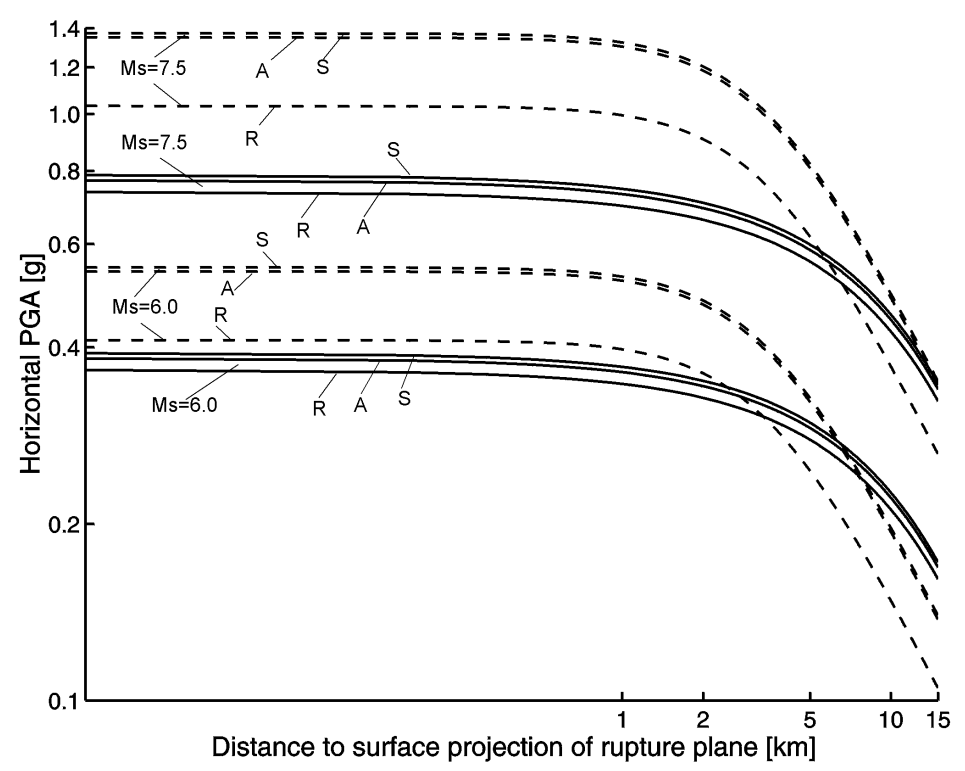

(a)

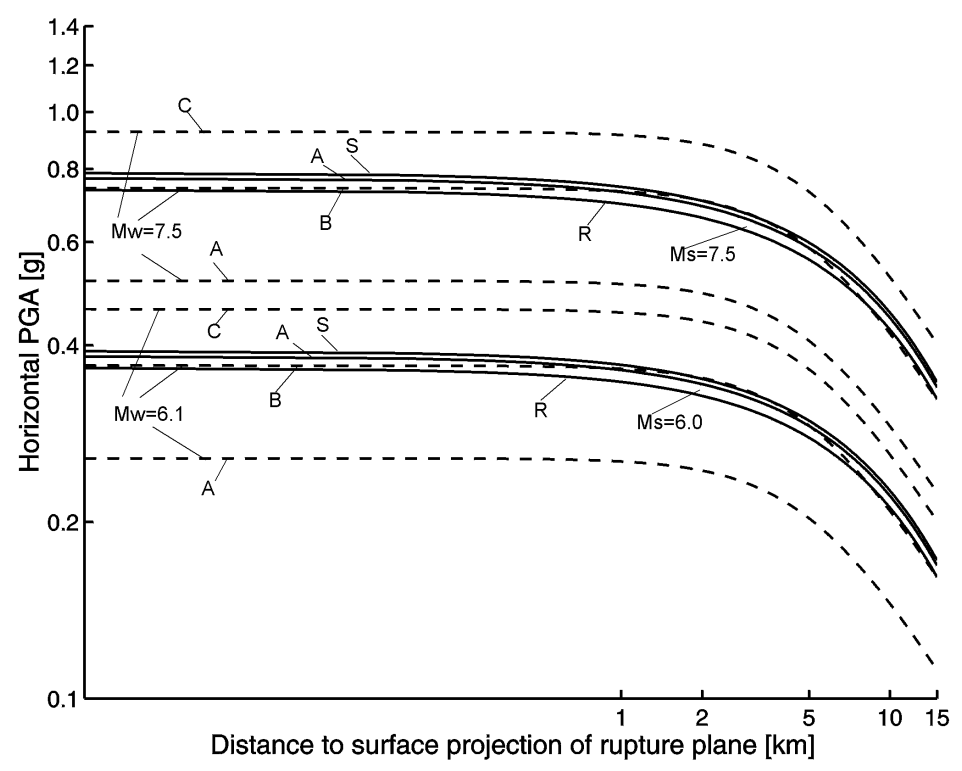

(b)

Fig. 2. 


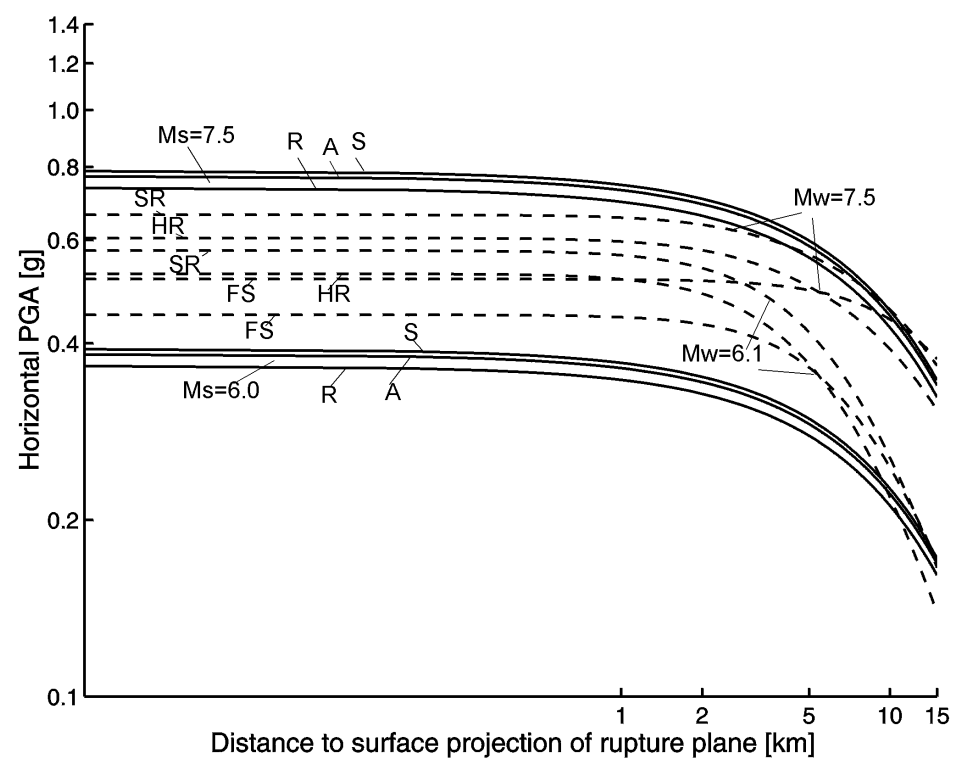

(c)

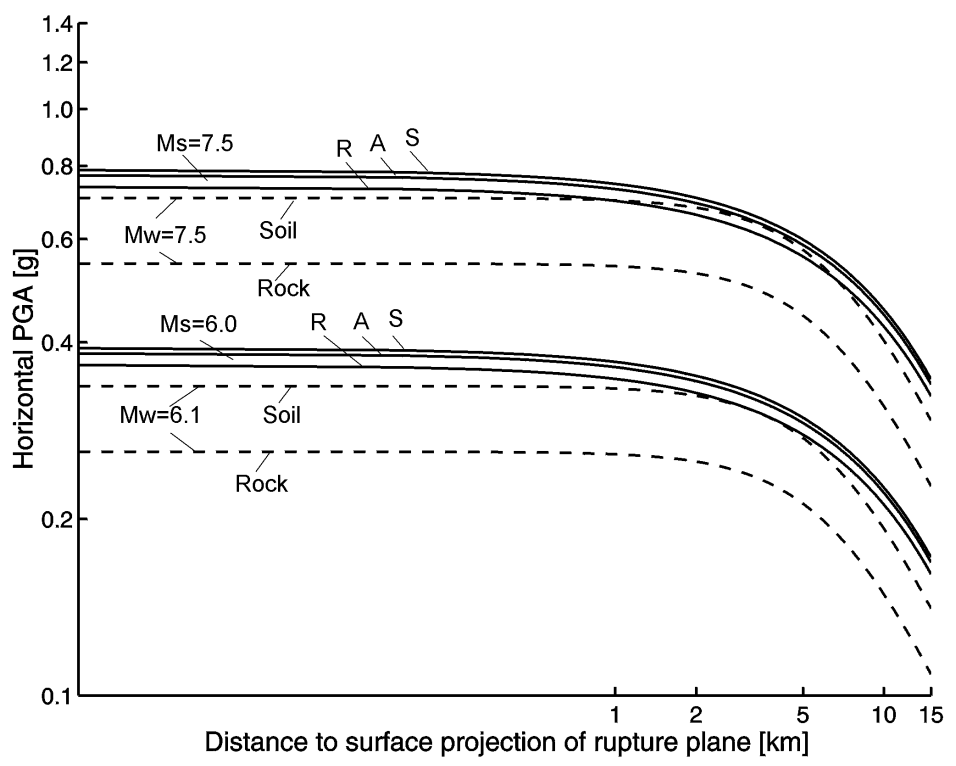

(d)

Fig. 2. Continued. 


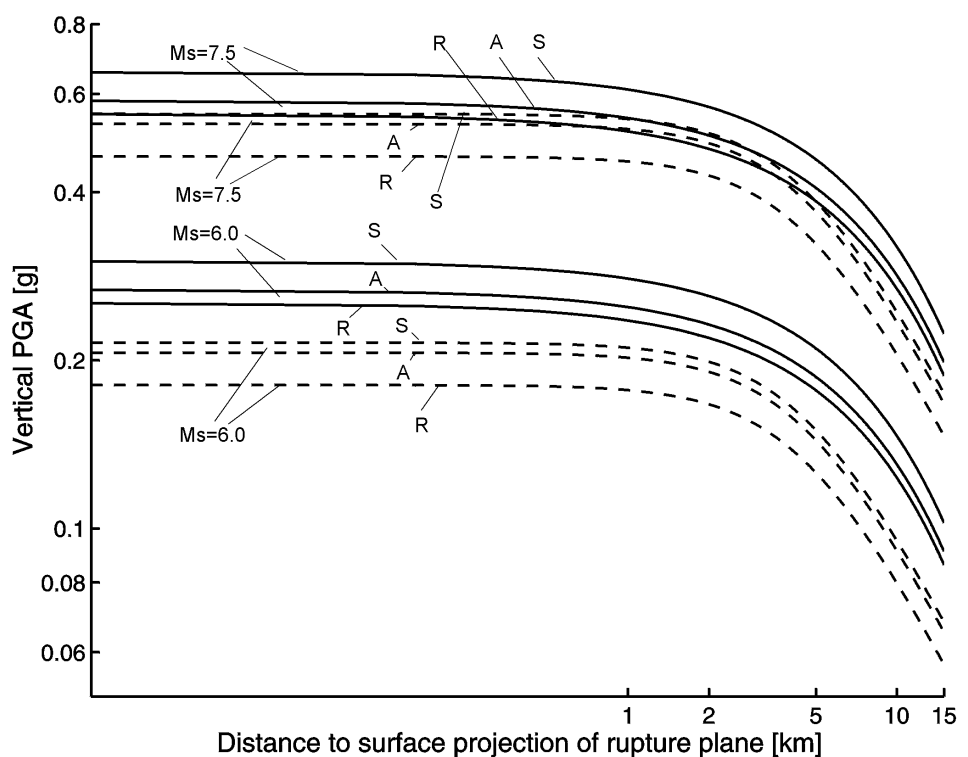

(a)

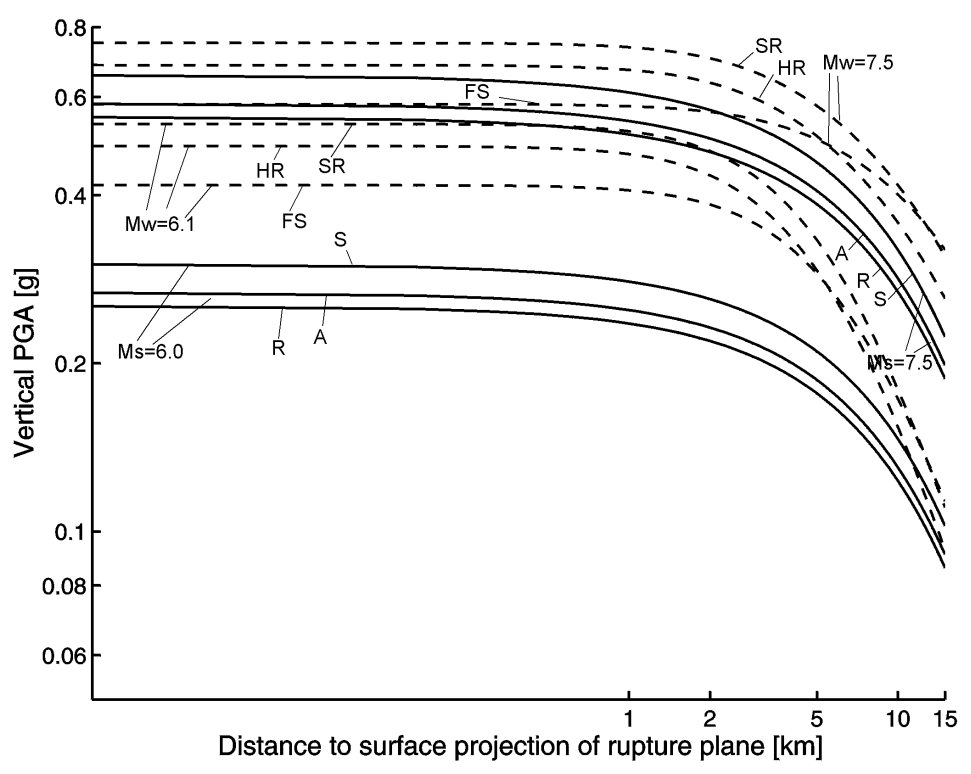

(b)

Fig. 3. 


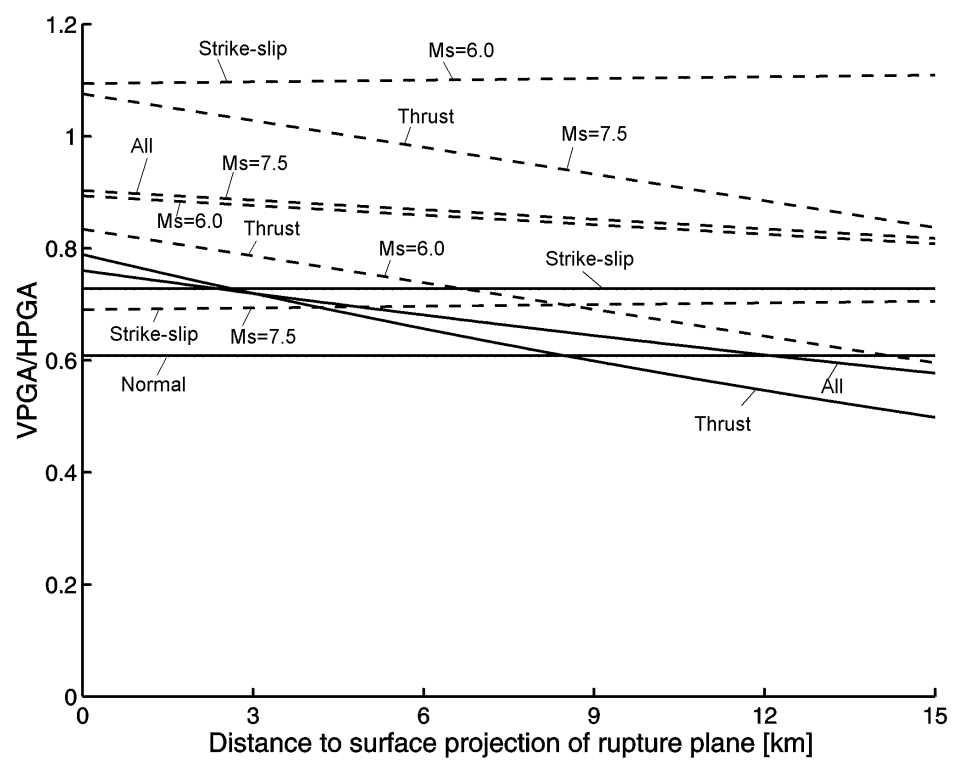

(a)

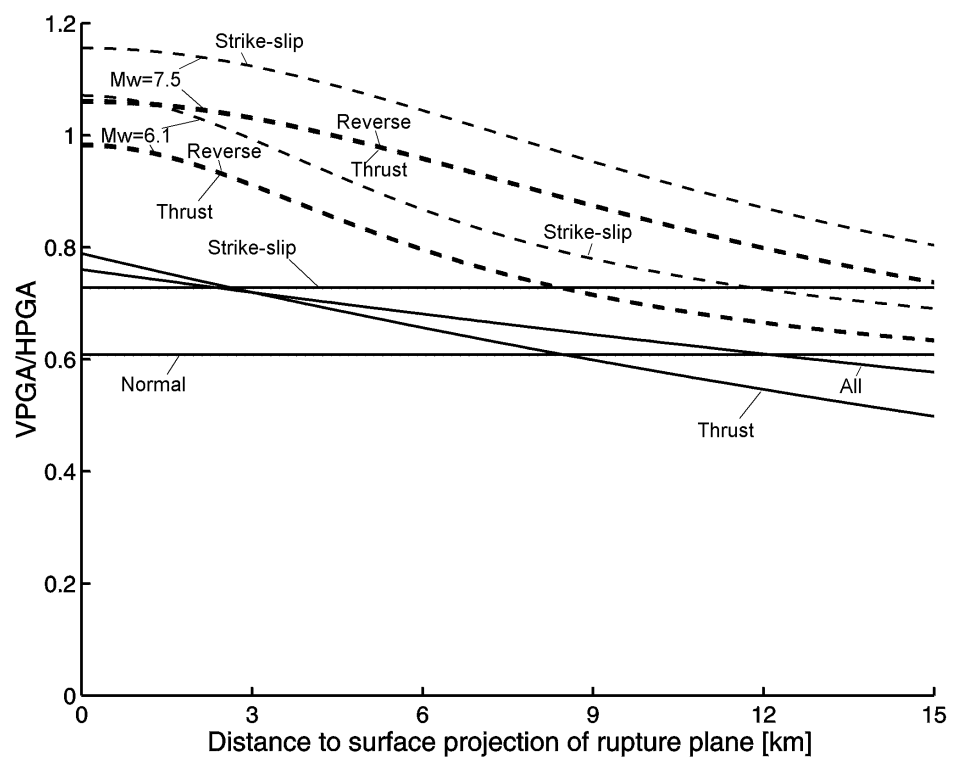

(b)

Fig. 4. 


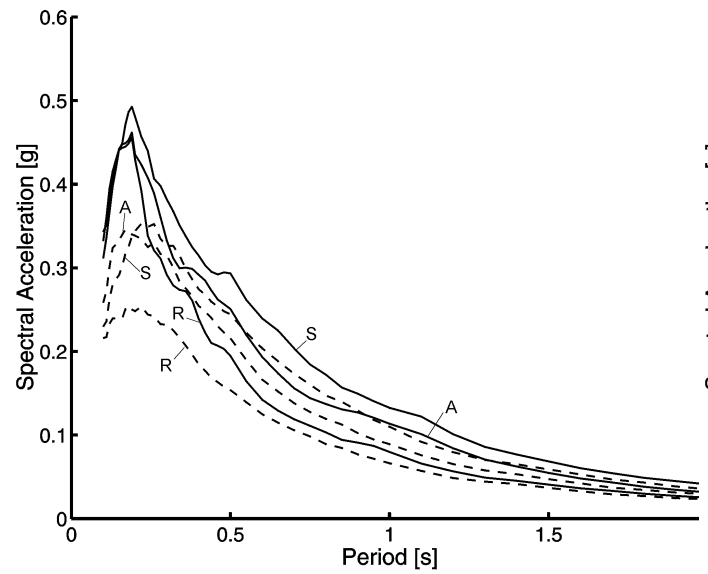

(a)

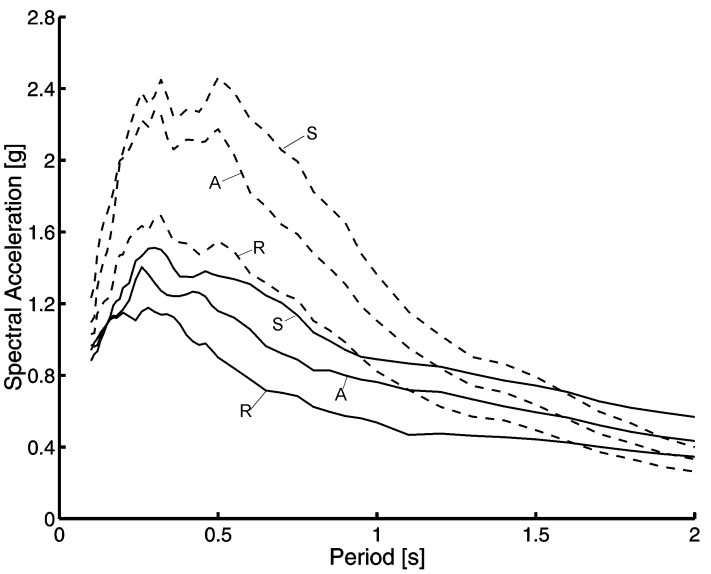

(b)

Fig. 5.

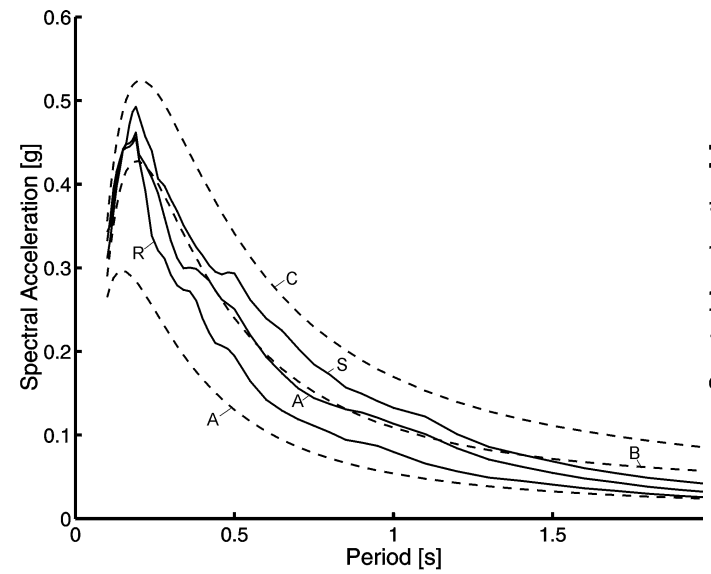

(a)

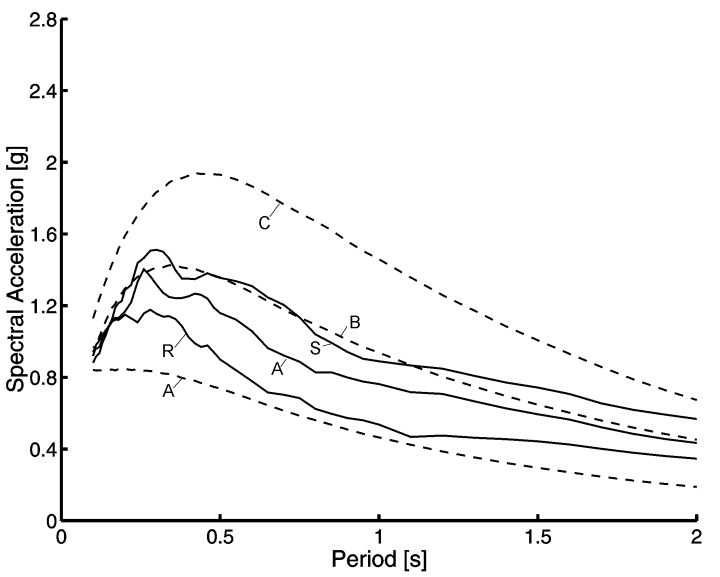

(b)

Fig. 6. 


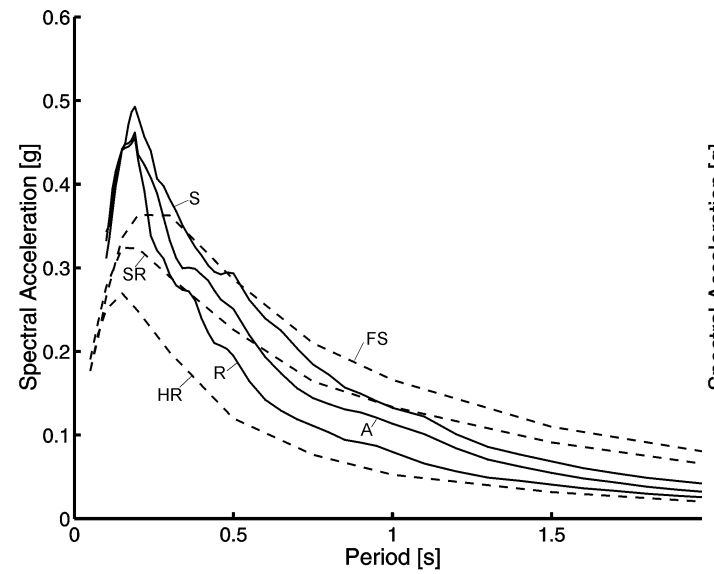

(a)

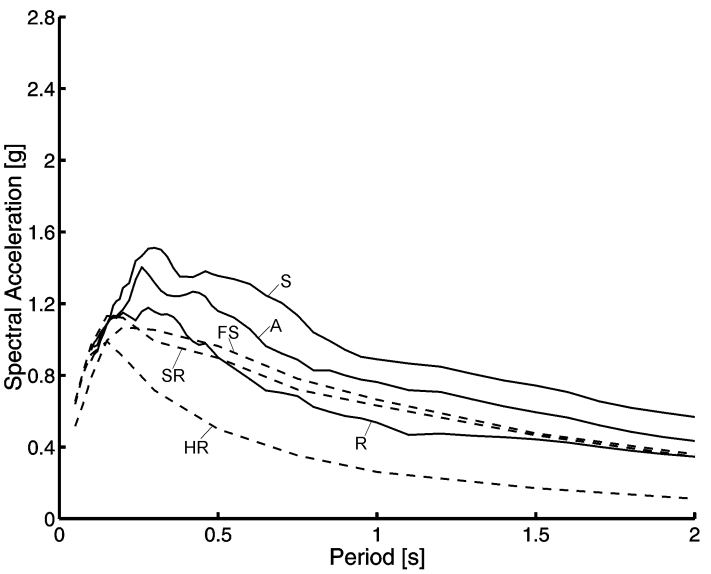

(b)

Fig. 7.

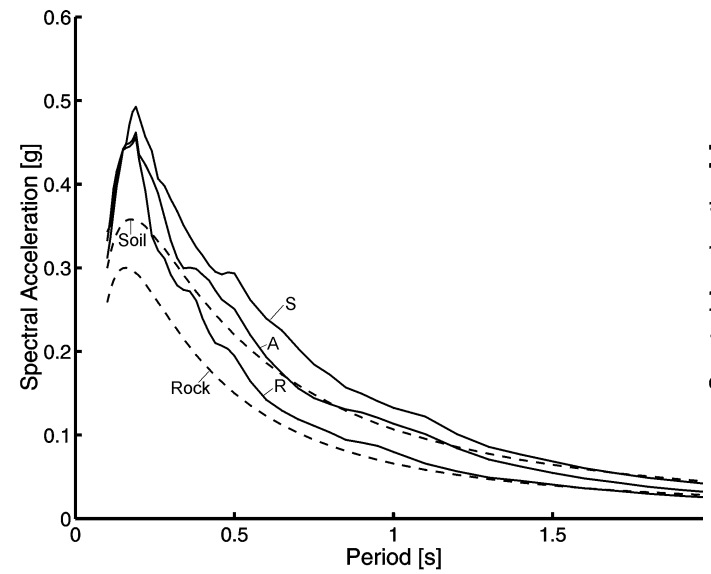

(a)

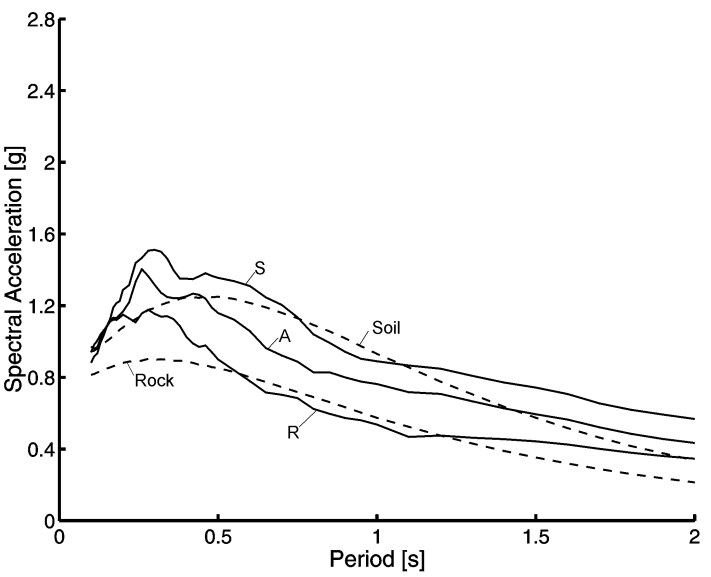

(b)

Fig. 8 . 


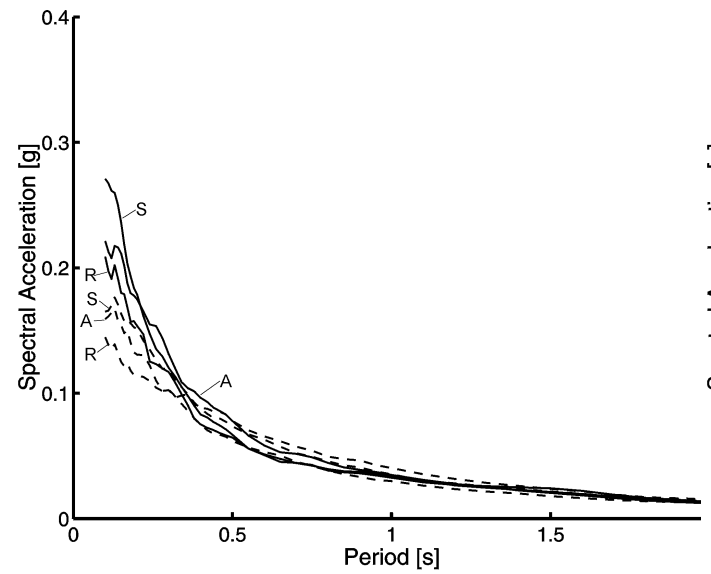

(a)

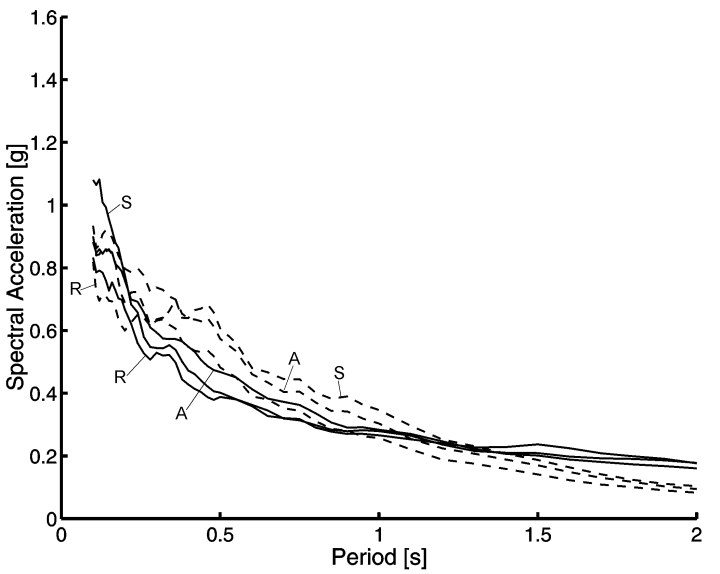

(b)

Fig. 9.

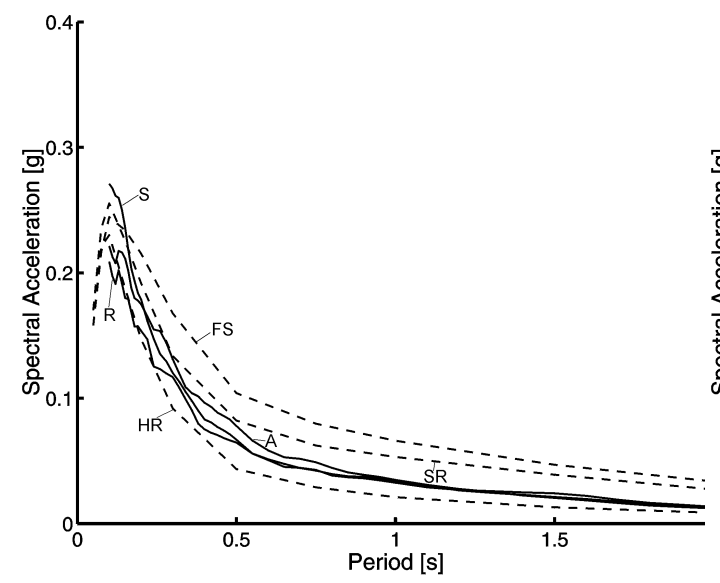

(a)

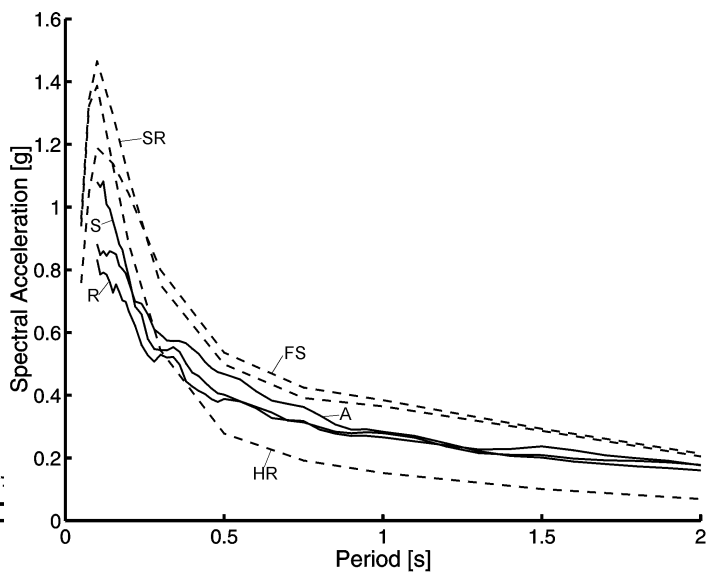

(b)

Fig. 10. 


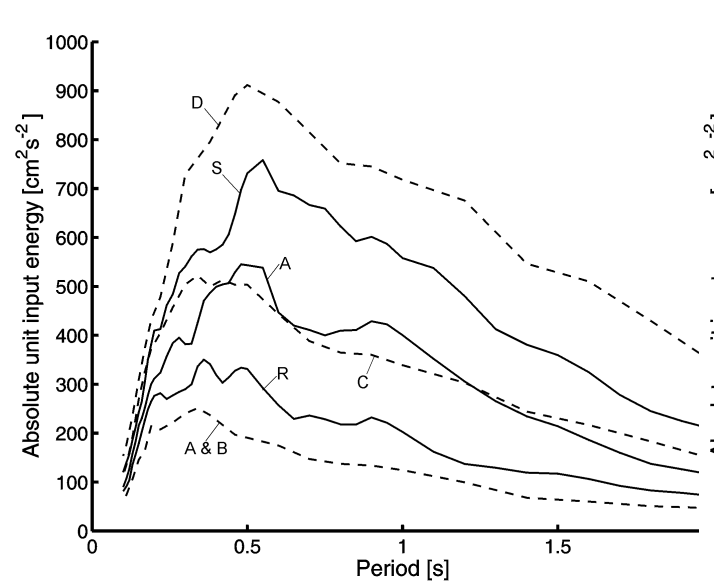

(a)

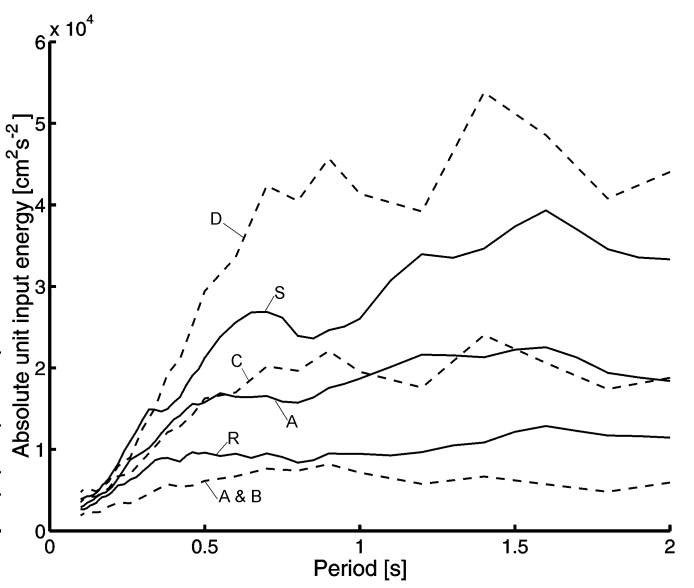

(b)

Fig. 11.

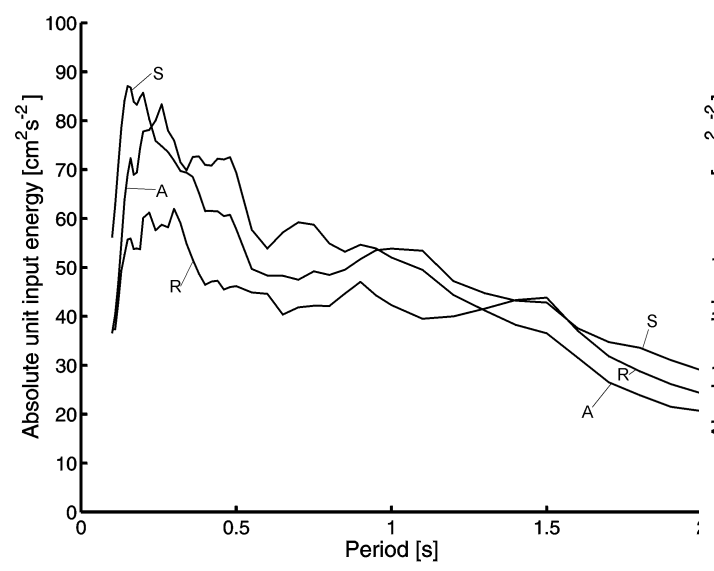

(a)

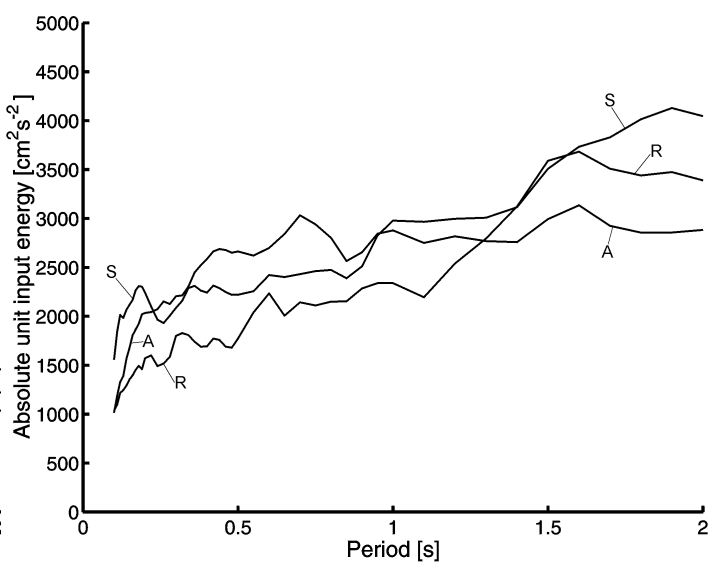

(b)

Fig. 12. 


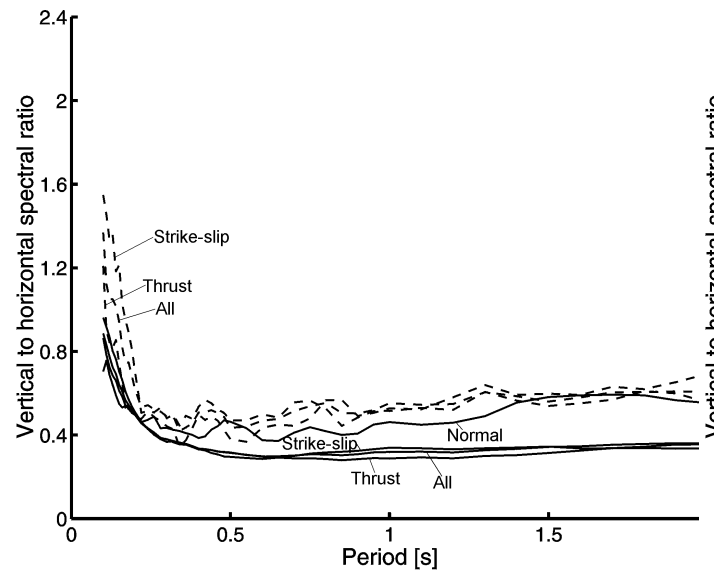

(a)

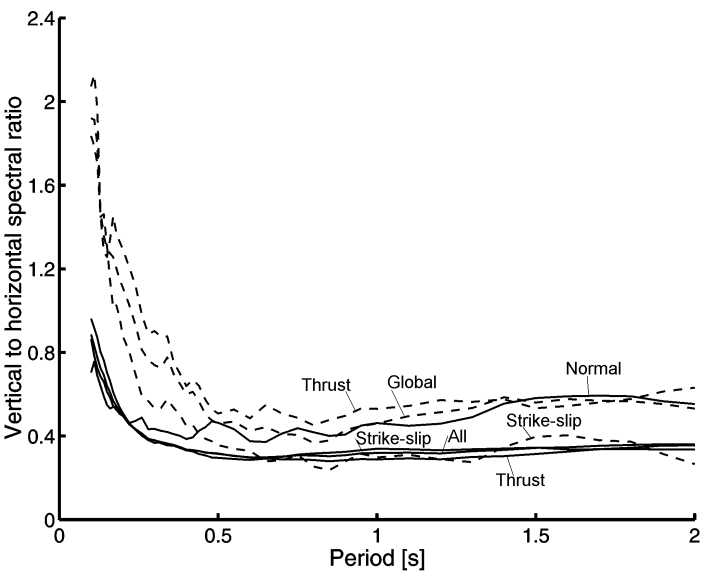

(b)

Fig. 13.

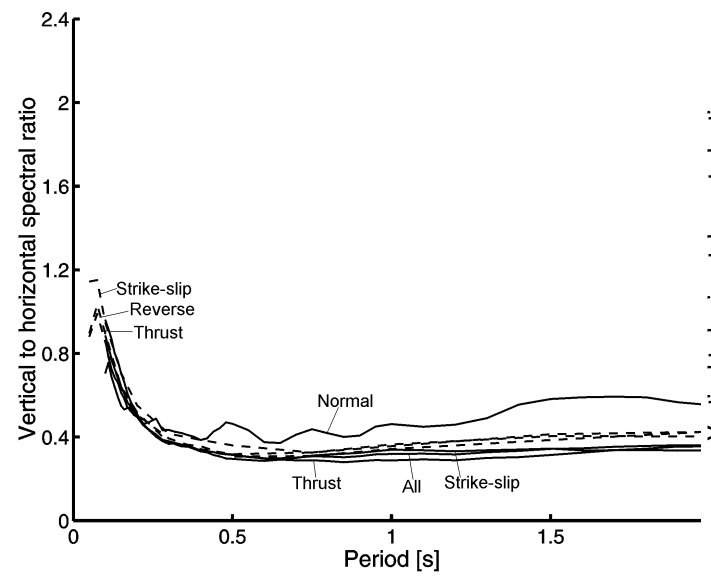

(a)

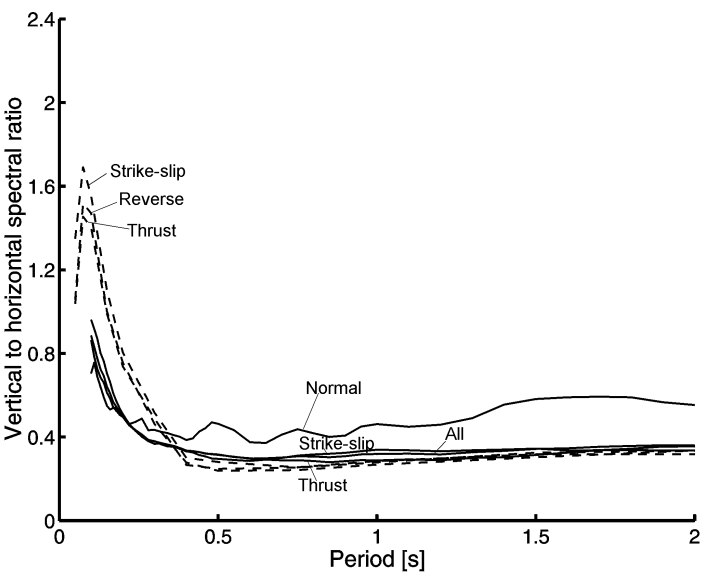

(b)

Fig. 14. 


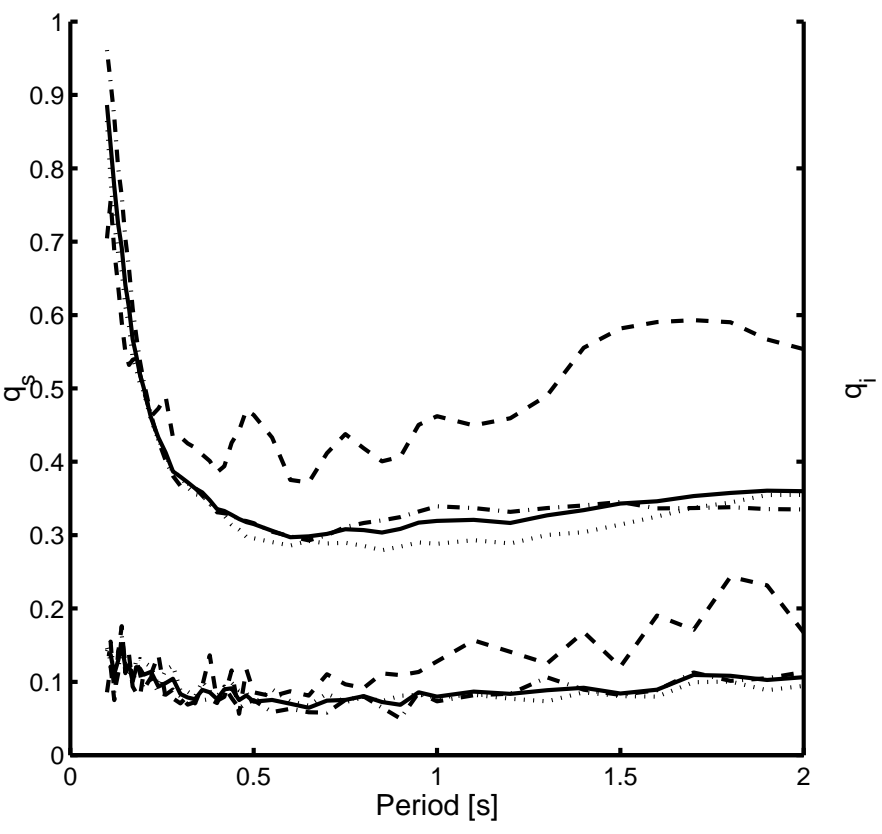

Fig. 15.

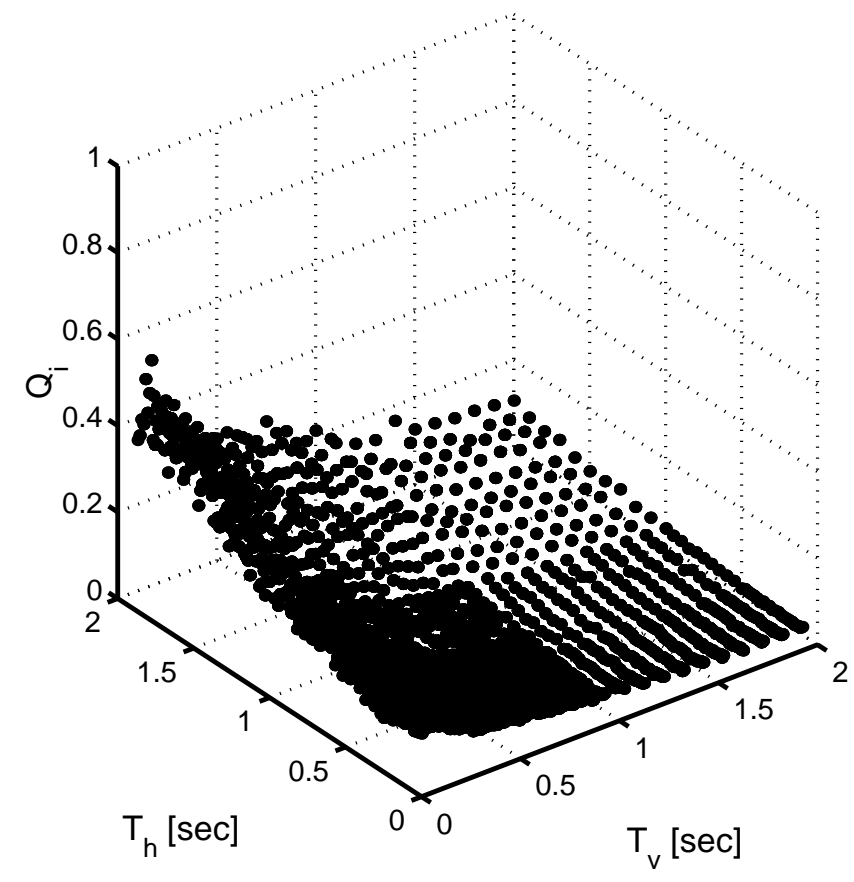

Fig. 16. 


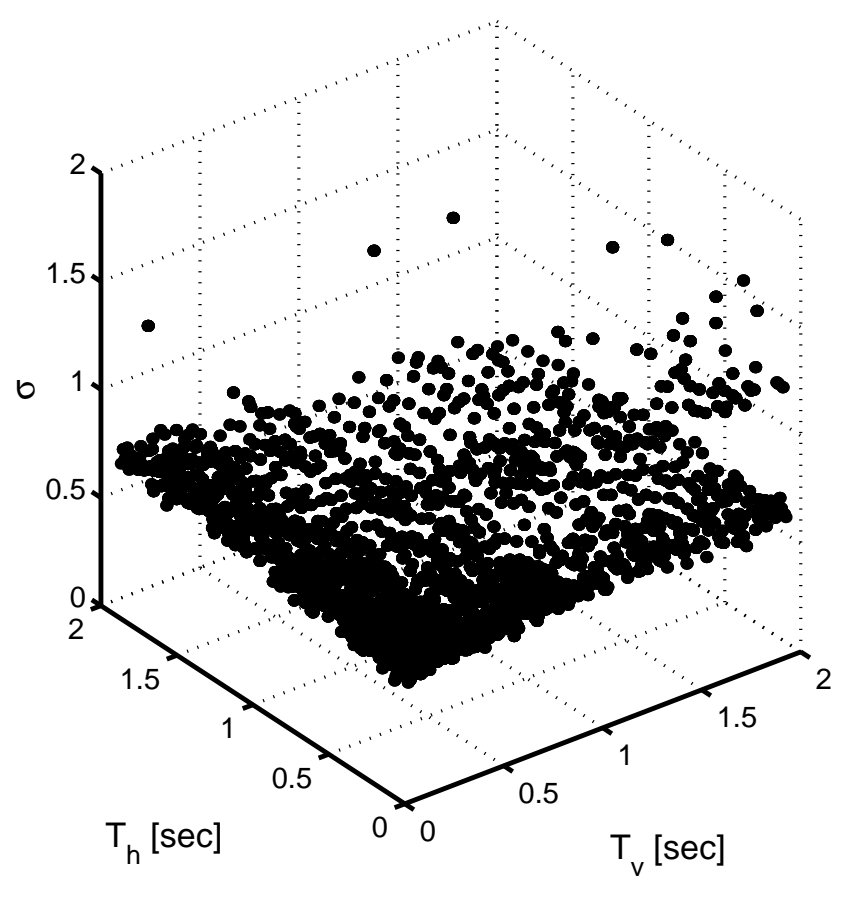

Fig. 17. 


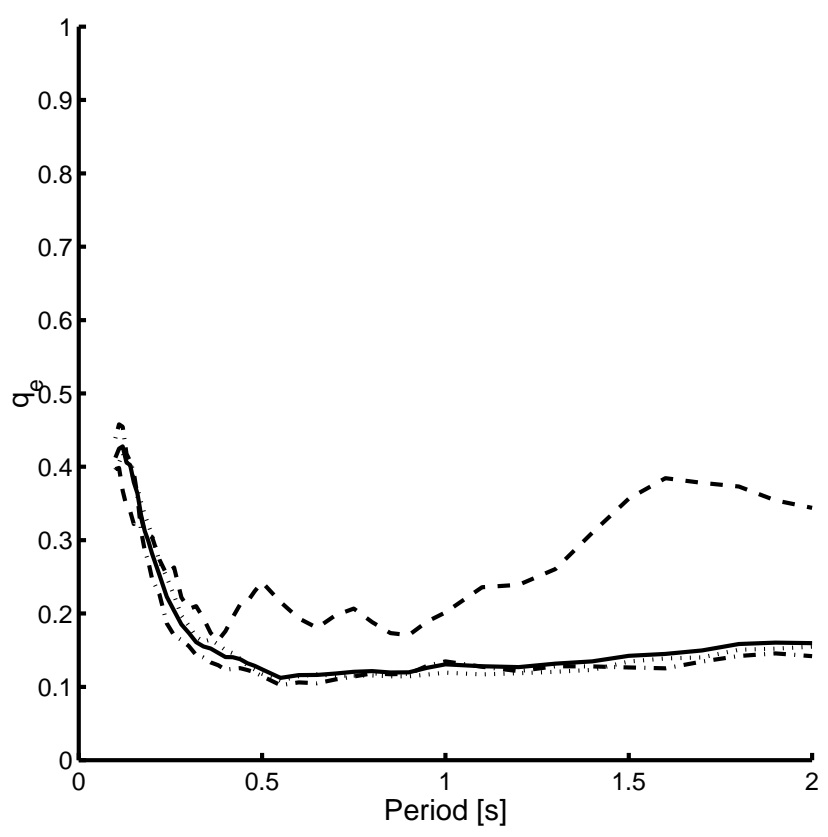

Fig. 18. 